Portland State University

PDXScholar

12-5-2005

\title{
Patterns of Risk and Trajectories of Preschool Problem Behaviors: a Person-Oriented Analysis of Attachment in Context
}

\author{
Thomas E. Keller \\ Portland State University, kellert@pdx.edu \\ Susan J. Spieker \\ University of Washington \\ Lewayne D. Gilchrist \\ University of Washington
}

Follow this and additional works at: https://pdxscholar.library.pdx.edu/socwork_fac

Part of the Social Work Commons

Let us know how access to this document benefits you.

\section{Citation Details}

Keller, T.E., Spieker, S.J., \& Gilchrist, L. (2005). Patterns of risk and trajectories of preschool problem behaviors: A person-oriented analysis of attachment in context. Development and Psychopathology, 17 ( 2 ), 349-384

This Article is brought to you for free and open access. It has been accepted for inclusion in Social Work Faculty Publications and Presentations by an authorized administrator of PDXScholar. Please contact us if we can make this document more accessible: pdxscholar@pdx.edu. 


\title{
Patterns of risk and trajectories of preschool problem behaviors: A person-oriented analysis of attachment in context
}

\author{
THOMAS E. KELLER,${ }^{a}$ SUSAN J. SPIEKER, ${ }^{b}$ AND LEWAYNE GILCHRIST ${ }^{b}$ \\ ${ }^{a}$ University of Chicago; and ${ }^{b}$ University of Washington
}

\begin{abstract}
A small proportion of children exhibit extreme and persistent conduct problems through childhood. The present study employed the multiple-domain model of Greenberg and colleagues as the framework for person-oriented analyses examining whether parent-child attachment combines with parenting, family ecology, and child characteristics in particular configurations of risk that are linked to this problematic developmental pathway. Using prospective data from a community sample of adolescent mothers and their children, latent variable growth mixture modeling identified a normative trajectory with declining problem behaviors during the preschool period. Consistent with research on early-starter pathways, a distinct group of children featured a higher intercept and a positive slope, indicating an escalation in disruptive behaviors. Attachment security played a role in defining specific risk profiles associated with the probability of exhibiting this problem trajectory. Given particular patterns of risk exposure, secure attachment served a protective function. Avoidant, but not disorganized, attachment was associated with significantly higher likelihood of the disruptive problem trajectory. The results also indicated the general accumulation of risk was detrimental, but the particular configuration of risk made a difference. Overall, the findings suggest early attachment operates in conjunction with personal and contextual risk to distinguish the development of later problem behaviors.
\end{abstract}

A pattern of extreme externalizing behaviors in the preschool years may be indicative of a trajectory toward conduct problems in childhood, adolescence, and adulthood (Campbell, 1995; Campbell, Shaw, \& Gilliom, 2000; Moffitt, 1993; Patterson, DeBaryshe, \& Ramsey, 1989; Robins, 1991). Most children demonstrate some disruptive behaviors as toddlers, but those with the most severe levels of disturbance have a greater likelihood of persist-

This research was supported by grants from the National Institute on Drug Abuse (DA05208) and the National Institute of Mental Health (MH52400, MH56599) and a National Service Research Award (MH20010). The authors thank Mary R. Gillmore, Diane M. Morrison, Steven Lewis, Mary Jane Lohr, Marilyn Gregory, the rest of the research team, and the study participants.

Address correspondence and reprint requests to: Thomas E. Keller, University of Chicago, School of Social Service Administration, 969 East 60th Street, Chicago, IL 60637; E-mail: tkeller@uchicago.edu. ing with conduct problems into the school years (Campbell, 1995). Longitudinal studies consistently reveal a small proportion of children, approximately 5-10\% within a given sample, who exhibit particularly serious conduct problems combined with an unusually high level of stability over time (Campbell et al., 2000; Moffitt, 1993). The identification of children who, starting from a very young age, maintain an extreme level of problem behaviors suggests a developmental trajectory qualitatively different from that of other children. "Earlystarter," "life-course persistent," and "childhood-onset" pathways have been proposed to account for children demonstrating this early onset and high continuity of conduct problems (Hinshaw, Lahey, \& Hart, 1993; Moffitt, 1993; Patterson, Capaldi, \& Bank, 1991). Explanations for these pathways stress the significance of early transactions between the child and environment, with negative patterns 
of parent-child interaction established in the home setting the stage for rejection by peers, academic failure, and other difficulties that contribute to continuing antisocial behavior. Although initial manifestations of a persistently problematic developmental pathway are suspected to be distinguishable at young ages, very few studies have used methodologies for analyzing individual behavioral trajectories during the period prior to school entry (Aguilar, Sroufe, Egeland, \& Carlson, 2000; Shaw, Gilliom, Ingoldsby, \& Nagin, 2003).

\section{Examining Early Conditions of Risk}

Extensive variable-oriented research has identified associations between early problem behaviors and numerous risk factors that occur at multiple levels of ecological organization (Campbell, 1995; Deater-Deckard, Dodge, Bates, \& Pettit, 1998; Greenberg, Speltz, \& DeKlyen, 1993; Lewis, Dlugokinski, Caputo, \& Griffin, 1988; Zeanah, Boris, \& Larrieu, 1997). The various domains implicated in the development of early problem behaviors include: characteristics of the child (e.g., gender, temperament), characteristics of the parent (e.g., mental health, antisocial behavior), parenting practices (e.g., teaching skills, child control strategies, attitudes), parent-child relationship (e.g., attachment, emotional availability), and family ecology (e.g., socioeconomic status [SES], stress, marital relations).

Beyond the identification of risk and protective factors, an essential task is to investigate how the complex interaction of factors early in life contributes to developmental pathways leading to healthy adjustment or mental health problems (Cicchetti \& Richters, 1993; Rutter, 1990; Sroufe, 1997; Sroufe \& Rutter, 1984). Individual development is dependent upon the particular matrix of risk and protection at multiple levels of ecological organization. A protective factor may be of little consequence in the absence of risk but crucial in buffering the effects of high-risk conditions (Rutter, 1985, 1990). Likewise, a single risk factor may not be enough to derail development, but the accumulation of multiple risks is typically detrimental (Sameroff, Seifer, \&
Bartko, 1997; Sanson, Oberklaid, Pedlow, \& Prior, 1991). As Bronfenbrenner (1977, p. 518) emphasized, "In ecological research, the principal main effects are likely to be interactions" (italics in original). Thus, a primary goal in developmental psychopathology is to determine the unique combinations of risk and protective factors probabilistically associated with diverse developmental outcomes (Cicchetti \& Cohen, 1995; Sroufe, 1997).

A "person-oriented approach" to research on individual functioning is consistent with a view of development involving complex interactions between personal, social, and environmental factors (Bergman \& Magnusson, 1997; Magnusson, 1995, 1998). A basic premise of the person-oriented approach is that developmental processes cannot be understood by examining single variables in isolation from other interacting factors. Instead, each factor derives its meaning and significance from its relations to the others, and individual development is a function of the pattern of contributing influences. This general approach, which focuses on distinguishing qualitatively different groupings of individuals, can be applied to identify diverse developmental processes as well as diverse outcomes. Consequently, it is well suited to the investigation of equifinality and multifinality in developmental pathways (Cicchetti \& Rogosch, 1996). Membership in a pattern-homogeneous subgroup based on developmental process factors can be related to membership in a pattern-homogeneous subgroup based on indicators of developmental outcome. For example, this approach can be used to examine the impact of particular constellations of risk factors by identifying subgroups with characteristic profiles across several risk indicators and then relating subgroup membership to a criterion indicating behavioral adjustment (Campbell et al., 2000; Stattin \& Magnusson, 1996).

\section{Attachment in a Model of Overlapping Domains of Risk}

A conceptual model for the development of childhood problem behaviors that places emphasis on the "necessary interrelation" of attachment and other risk factors has been 
proposed by Greenberg and colleagues (1993, p. 193, italics in original). This model (see also Greenberg, 1999; Greenberg, Speltz, DeKlyen, \& Jones, 2001) focuses on interactions among four domains of risk commonly identified as antecedents of problem behaviors: child biologic characteristics, parental management and socialization practices, family ecology, and the quality of early attachment relations. Because Greenberg and colleagues have previously reviewed and discussed the relevance of these domains for understanding the origins of conduct problems (Greenberg, 1999; Greenberg et al., 1993), only key factors in each domain are presented here. Child biologic characteristics include gender, temperament, intellectual functioning, and individual differences in psychophysiological reactivity (e.g., Eisenberg \& Fabes, 1992; Keenan \& Shaw, 1997; Lahey, Waldman, \& McBurnett, 1999; Rothbart \& Bates, 1998). The parenting domain encompasses a host of attitudes, beliefs, practices, and behaviors such as the degree of parental warmth and approval, the nature of motivation and guidance, the strategies used for discipline and punishment, and the quality of parent-child interaction (e.g., Dishion, French, \& Patterson, 1995; Rothbaum \& Weisz, 1994). Likewise, the domain of family ecology represents a diverse set of parent and community characteristics that have been associated with disruptive child behavior, including parental characteristics (e.g., psychiatric illness, criminality), family functioning (e.g., family violence), environmental provisions (e.g., poverty, SES), stressful life events (e.g., divorce, transitions), and social support resources (e.g., Rutter, Cox, Tupling, Berger, \& Yule, 1975; Sameroff et al., 1997; Shaw, Vondra, Hommerding, Keenan, \& Dunn, 1994).

The role of attachment in the development of disruptive behavior problems receives special attention in the model proposed by Greenberg and colleagues (1993). According to theory, the attachment behavioral system promotes proximity to a caregiver for protection under conditions of stress or threat. Experiencedependent expectancies regarding caregiver availability and responsiveness have implications for how the child subsequently regulates internal states, engages with the environment, and elicits security when anxious or distressed (Bretherton, 1985; Carlson \& Sroufe, 1995). For example, children with secure attachment organization, who think of themselves as worthy of care and effective in attaining it, may be more likely to solicit emotional support to cope with stressful events or chronic adversity, thereby buffering the effects of a negative environment (Rutter, 1985). In contrast, children who have experienced caregivers as unavailable, inconsistent, or rejecting may be less likely to see the value of turning to others in times of stress.

Attachment insecurity in itself is not considered pathological, nor is it causally or deterministically related to the development of psychopathology (Rutter, 1995; Sroufe, 1997). Rather than a direct, linear pathway from early attachment organization to later disorder, it is hypothesized that adaptation is the joint product of attachment history and current circumstances (Bowlby, 1973; Sroufe, Carlson, Levy, \& Egeland, 1999). Thus, insecure attachment organization is not considered necessary or sufficient to cause behavioral disorder. Instead, attachment history is suspected to operate as a risk or protective factor influencing behavior in the context of other risks (Carlson \& Sroufe, 1995; Greenberg, 1999).

Attention to this proposition of attachment theory aids in the interpretation of heterogeneous results from studies attempting to link infant attachment assessed in the Strange Situation to externalizing problem behaviors in the preschool years. In low-risk, middle-class samples, the findings have been inconsistent. Some studies have observed main effects of attachment (Burgess, Marshall, Rubin, \& Fox, 2003), while others have failed to do so (Bates, Maslin, \& Frankel, 1985; Goldberg, Gotowiec, \& Simmons, 1995). In other cases, gender interacted with attachment such that girls with insecure-avoidant attachment were rated more difficult by teachers (Fagot \& Kavanagh, 1990), but girls with insecure-resistant classifications exhibited fewer externalizing behaviors than other children (Lewis, Feiring, McGuffog, \& Jaskir, 1984). As would be expected, however, the results for studies of children in high-risk, low-income families have 
more consistently demonstrated connections between insecure attachment and externalizing problem behaviors (Erickson, Sroufe, \& Egeland, 1985; Lyons-Ruth, Alpern, \& Repacholi, 1993; Shaw \& Vondra, 1995).

Furthermore, researchers examining those cases with elevated or clinical level problem behaviors for antecedent conditions have noted the importance of attachment insecurity in conjunction with additional parent, child, and environmental risks (Erickson et al., 1985; Lewis et al., 1984; Lyons-Ruth et al., 1993; Munson, McMahon, \& Spieker, 2001; RadkeYarrow, McCann, DeMulder, Belmont, Martinez, \& Richardson, 1995; Shaw, Owens, Vondra, Keenan, \& Winslow, 1996). Recently, for example, Burgess et al. (2003) reported that insecure attachment interacted with difficult child temperament in predicting high levels of externalizing behavior. Similarly, a large, prospective study using data from the NICHD Study of Early Child Care found that attachment classification at 15 months interacted with an index of cumulative contextual risk in the prediction of problem behaviors at 3 years of age (Belsky \& Fearon, 2002).

\section{Insecure Attachment and Externalizing Behaviors}

Consistent with the multiple pathways framework of developmental psychopathology, particular forms of insecure attachment may influence the development of conduct problems via different mechanisms. For example, children with insecure-avoidant classifications who have been neglected or rejected by caregivers may have working models of relationships that are tinged with anger, resentment, and mistrust due to their unmet emotional needs (Bowlby, 1973). As a consequence, they may enter social interactions with heightened sensitivity to rejection (Downey, Lebolt, Rincon, \& Freitas, 1998) and with attributional biases that interpret the intent of other people's actions as negative or hostile (Cassidy, Kirsh, Scolton, \& Parke, 1996; Suess, Grossman, \& Sroufe, 1992). In turn, these negative and defensive attributional biases can lead to reactive aggression (Crick \& Dodge, 1994; Dodge,
1993). Considerable evidence suggests a prospective link between avoidant attachment and externalizing behaviors (Burgess et al., 2003; Erickson et al., 1985; Fagot \& Kavanagh, 1990; Goldberg, 1997; Munson et al., 2001; Renken, Egeland, Marvinney, Mangelsdorf, \& Sroufe, 1989).

Children with insecure-disorganized attachments due to a frightening, abusive parent or a frightened parent with unresolved loss are considered to be at particularly high risk for psychopathology (Lyons-Ruth, 1996; Main \& Hesse, 1990). As one potential pathway to conduct problems for this very heterogeneous attachment category, some children are thought to respond to the fear, disorientation, or chaos in their caregiving environment by developing a controlling-punitive stance toward the parent as they get older (Main \& Cassidy, 1988; Teti, 1999). The controlling-punitive behavior is angry and domineering, with attempts to humiliate, embarrass, or reject the parent. Several researchers have found disorganized attachment to predict subsequent conduct problems (Carlson, 1998; Lyons-Ruth et al., 1993; Munson et al., 2001; Shaw et al., 1996). In addition, a recent meta-analysis of 12 studies found a modest correlation between disorganization and externalizing behaviors $(r=.29)$, although half these studies assessed attachment status in the preschool period contemporaneous with the measurement of problem behaviors (van IJzendoorn, Schuengel, \& Bakermans-Kranenburg, 1999).

Finally, children with insecure-resistant attachment arising from inconsistent caregiving are characterized by hyperactivating emotional strategies and may display frustration, overstimulation, and impulsivity (Cassidy, 1994). Although these features of poor selfregulation appear consistent with the development of disruptive behaviors, few studies have analyzed the effects of insecure-resistant attachment on problem behaviors due to typically low frequencies of this classification. However, the little evidence that does exist suggests that insecure-resistant children are more likely to be dependent and needy than hostile and destructive (Cassidy \& Berlin, 1994; Lewis et al., 1984; Renken et al., 1989). 


\section{Examining the model of overlapping risk}

The model presented by Greenberg and colleagues highlights the importance of understanding how specific patterns of overlapping risk contribute to developmental processes. Certain risk domains may exert greater influence than others, certain domains may be more strongly associated with certain disorders, and different combinations of factors may lead to different disorders (Greenberg, 1999). The examination of whether certain risk factors or certain combinations of risk factors matter more than others can be accomplished with person-oriented analyses. Greenberg et al. (1993) recommend developing individual child/family profiles based on the number and type of interrelations among the different risk factors and charting the outcomes of individuals who share common profiles. However, the process of sorting out the ways in which the multiple risk domains may combine to influence the likelihood of childhood disorders has barely begun. Greenberg and colleagues have reported cross-sectional studies based on this model comparing clinic-referred boys to matched nonreferred boys (Greenberg, DeKlyen, Speltz, \& Endriga, 1997; Greenberg et al., 2001). Although their findings are consistent with the notion that the sheer accumulation of risk factors is significant, they also suggest the domains may be differentially predictive of psychopathology (Greenberg et al., 2001).

Unraveling the complex interplay of factors influencing behavioral pathways leading to adjustment or disorder requires prospective studies tracing development from a young age (Cicchetti \& Richters, 1993). To avoid problems related to restricted range on key variables, studies should employ samples of children at risk for development of mental health problems, that is, exposed to multiple risk factors and exhibiting relatively high base rates of psychopathology (Greenberg, 1999). These criteria suggest that adolescent mothers and their children are an important high-risk population for examining the development of early problem behaviors. Children of adolescent mothers are more likely to experience elevated levels of environmental risk, re- flected in low SES, low maternal education, high levels of maternal depression, as well as less sensitive and more punitive parenting ( $\mathrm{Co}-$ ley \& Chase-Lansdale, 1998; Osofsky, Hann, \& Peebles, 1993). Adolescent mothers and their children tend to show lower rates of secure attachment and higher rates of insecure-avoidant and insecure-disorganized classifications than less stressed samples (Spieker \& Bensley, 1994; Ward \& Carlson, 1995). Likewise, the children of adolescent mothers have a greater likelihood of demonstrating problem behaviors, poor school performance, and high levels of distractibility and aggression early in life (Brooks-Gunn \& Furstenberg, 1986; Spieker, Larson, Lewis, White, \& Gilchrist, 1997).

\section{The Present Study}

In the present study, a person-oriented analysis based on the Greenberg model is conducted on a sample of children born to adolescent mothers. The purpose is to identify particular configurations of overlapping risks associated with distinct trajectories of disruptive problem behaviors. A fundamental premise guiding the study is that early attachment operates in conjunction with other factors in the child's ecology to influence problem behaviors. It is hypothesized that attachment organization will play a greater role in distinguishing child behavior trajectories in the context of conditions of risk or adversity. In particular, it is expected that insecure attachment combined with high levels of risk in other domains will increase the likelihood of a problematic behavior trajectory. A secondary hypothesis is that an increase in the number of high-risk domains should be associated with an increased probability of a problem behavior trajectory (Shaw et al., 1994; Shaw, Winslow, Owens, \& Hood, 1998).

This first comprehensive, prospective investigation using the Greenberg model with a nonclinical sample represents a systematic effort to identify which individuals, by virtue of their early risk profile, are likely to exhibit a particular trajectory of problem behaviors during the preschool years. Following the logic of person-oriented research, children are first classified according to problem behavior tra- 
jectory. Likewise, they are independently classified according to within-domain risk profiles for each of the four domains in the model. Next, the likelihood of children with particular cross-domain risk combinations displaying certain trajectories of problem behavior is determined. The objective is to identify configurations of early risk linked with subsequent problem behaviors more often than expected by chance (types) or occurring less often than expected by chance (antitypes; Bergman \& Magnusson, 1997). Using the Greenberg model to define children according to patterns of cross-domain risk before testing for the probability of showing problem behaviors distinguishes this study from most previous studies examining attachment organization in conjunction with additional risks. Studies typically have used post hoc approaches (backward prediction) to find factors associated with established clinical status (see Lyons-Ruth et al., 1993).

\section{Method}

\section{Sample and procedures}

The data for this study are from an ongoing natural history study tracing the development of adolescent mothers and their children. Research has been reported on developmental trajectories of preschool problem behaviors for the initial cohort of the study (Spieker, Larson, Lewis, Keller, \& Gilchrist, 1999), but the current study represents the first analysis of data from a separate, second cohort of the study. Recruitment of pregnant adolescents for participation in the second cohort occurred at public and private hospital prenatal clinics, public school alternative programs, and social service agencies located in a metropolitan region. Recruitment included advertising, so a conventional response rate could not be determined. However, when similar recruitment strategies were used for the first cohort, approach and consent data available from one location (a hospital prenatal clinic) indicated that $75 \%$ of eligible adolescents enrolled. All recruitment, consent, and data collection efforts followed Institutional Review Board approved protocols.
At the time of entry into the study, respondents were unmarried pregnant adolescents, aged 17 or younger, who were planning to carry their pregnancies to term. A total of 255 pregnant adolescents were enrolled in the study and completed the initial interview between June, 1992 and September, 1993. Based on national statistics for the race and ethnicity of unmarried adolescents giving birth during the same period from 1992 to 1993 (National Center for Health Statistics, 1994, 1995), the study sample has a comparable percentage of Caucasians (56\% nationally vs. $59 \%$ this sample), fewer African Americans (41 vs. 22\%), and more in other racial categories (3 vs. 19\%) such as Biracial, Asian/Pacific Islander, and Native American. The study sample closely reflects the racial distribution for adolescents who had babies in the local study area during 1992-1993 (Seattle-King County Department of Health, 1998).

The majority of study participants $(71 \%)$ were experiencing their first pregnancy, and almost all (97\%) planned to parent the baby rather than place the child for adoption. Participants ranged in age from 12 to $17(M=$ 16.0 years, $S D=1.0$ ) and had completed an average of 9.2 years of formal education $(S D=$ 1.3). A substantial proportion of the sample gave indications of difficult family backgrounds: $41 \%$ had parents receiving public assistance in the previous year; $50 \%$ had parents who were divorced; $54 \%$ had run away from home at least once; and $20 \%$ had been in foster care at some point while growing up (Table 1).

Initial interviews with study participants were conducted during pregnancy, and subsequent interviews were completed every 6 months postpartum through the first 36 months of the child's life. Following the 12-month postpartum interview, mother and child visited a university laboratory for videotaping of the Strange Situation procedure for assessment of mother-child attachment. The structured interviews, conducted by highly experienced research interviewers, averaged $2 \mathrm{hr}$ in length and typically took place in respondents' homes. Variables measured in the interviews included demographic characteristics, pregnancy history, relationships and social sup- 
Table 1. Comparison of cases in original sample and study sample

\begin{tabular}{|c|c|c|c|c|}
\hline & $\begin{array}{c}\text { Whole } \\
\text { Sample } \\
(n=255)\end{array}$ & $\begin{array}{c}\text { Study } \\
\text { Sample } \\
(n=169)\end{array}$ & $\begin{array}{l}\text { Excluded } \\
(n=86)\end{array}$ & $\begin{array}{l}\text { Included } \\
\text { vs. } \\
\text { Excluded }\end{array}$ \\
\hline Race/ethnicity & & & & $\begin{array}{c}\chi^{2}=1.9, d f=5 \\
p=.86\end{array}$ \\
\hline White & $59 \%$ & $60 \%$ & $58 \%$ & \\
\hline African American & $22 \%$ & $21 \%$ & $23 \%$ & \\
\hline Biracial (Black/White) & $6 \%$ & $6 \%$ & $4 \%$ & \\
\hline American Indian & $4 \%$ & $4 \%$ & $3 \%$ & \\
\hline Asian/Pacific Islander & $4 \%$ & $4 \%$ & $6 \%$ & \\
\hline Other & $5 \%$ & $5 \%$ & $6 \%$ & \\
\hline First pregnancy & $71 \%$ & $73 \%$ & $69 \%$ & $t=0.70, p=.49$ \\
\hline Plan to parent baby & $97 \%$ & $99 \%$ & $93 \%$ & $t=2.00, p=.05$ \\
\hline \multicolumn{5}{|l|}{ Mean years $(S D)$} \\
\hline Age & $16.04(1.02)$ & $16.09(0.99)$ & $15.95(1.06)$ & $t=1.00, p=.32$ \\
\hline Education & $9.20(1.28)$ & $9.19(1.27)$ & $9.21(1.29)$ & $t=0.12, p=.91$ \\
\hline \multicolumn{5}{|l|}{ Parents } \\
\hline Public assistance & $41 \%$ & $43 \%$ & $38 \%$ & $t=0.72, p=.47$ \\
\hline Divorced & $50 \%$ & $51 \%$ & $49 \%$ & $t=0.31, p=.76$ \\
\hline Ran away from home & $54 \%$ & $54 \%$ & $53 \%$ & $t=0.05, p=.96$ \\
\hline Foster care experience & $20 \%$ & $15 \%$ & $29 \%$ & $t=2.40, p=.02$ \\
\hline \multicolumn{5}{|l|}{ Secure attachment } \\
\hline 12 months $(n=189)$ & $42 \%$ & $42 \%$ & $40 \%$ & $t=0.17, p=.86$ \\
\hline \multicolumn{5}{|l|}{ Disruptive behavior } \\
\hline 24 months $(n=212)$ & $7.17(3.18)$ & $7.30(3.17)$ & $6.72(3.19)$ & $t=1.10, p=.27$ \\
\hline 30 months $(n=214)$ & $7.17(3.22)$ & $7.14(3.13)$ & $7.28(3.56)$ & $t=0.25, p=.80$ \\
\hline 36 months $(n=210)$ & $5.68(3.37)$ & $5.63(3.15)$ & $5.87(4.11)$ & $t=0.36, p=.72$ \\
\hline 54 months $(n=181)$ & $5.26(3.03)$ & $5.09(3.08)$ & $6.22(2.59)$ & $t=1.79, p=.07$ \\
\hline
\end{tabular}

port, drug use and delinquency, psychosocial functioning, parenting, and the child's developmental progress. Depending on the assessment occasion, respondents received \$25-\$35 for completing the interviews. Attrition over the first five waves of data collection was minimal, with interview completion rates typically above $95 \%$. At 54 months postpartum, a subsample $(N=204)$ was selected for additional follow-up interviews. Criteria for selection were completion of either the Strange Situation procedure at 12 months or a child language assessment at 36 months. Interviews were completed with 184 members of the selected subsample (90\%) at 54 months.

As is common in longitudinal research, the sample for particular analyses depended upon patterns of missing data for the relevant variables. For the first phase of the analysis, within-domain categorization, the empirical classification procedures made use of all data available on the variables representing a par- ticular domain. Thus, for each domain, individuals were classified according to cutoffs or subgroups generated from the largest and most representative sampling of adolescent mothers with existing data. As described below, variables for the domains of child characteristics, parental management and socialization, and family ecology were selected to correspond with the risk factors outlined by Greenberg et al. (1993). Because most of these variables were assessed at multiple time points, the measures were averaged to reflect conditions over time before being used in the classification procedures. The number of cases with valid classifications in each domain was as follows: child characteristics $(N=236)$; parental management and socialization $(N=$ 204); and family ecology $(N=249)$. For the domain of parent-child attachment, Strange Situation assessments were obtained at 12 months for $74 \%$ of the original sample $(N=$ 189). Reasons for not completing the Strange 
Situation included miscarriages and infant deaths, infant adoptions, children were no longer in their mother's custody, or respondents had moved too far away to visit the laboratory. Child problem behaviors were assessed at 24, 30, 36, and 54 months. Using the missing data and classification procedures described below, membership in a particular behavior trajectory class was established for 194 cases (76\% of original sample).

The cross-domain analyses necessarily were limited to the dyads with valid data on the domains being investigated. Because the final cross-domain analyses examined links between attachment and behavior trajectories, the final sample contained the 169 cases with data on both of these variables ( $66 \%$ of original sample). ${ }^{1}$ Comparing these 169 cases to all cases excluded from the final analyses on maternal demographic characteristics and family history revealed only two statistically significant differences (Table 1). Mothers not in the study were less likely to have planned to keep their babies and were more likely to have been in foster care during their youth. Furthermore, comparisons of included and excluded cases on attachment security and child disruptive behavior showed no statistically significant differences, although problem behavior at the final time point approached significance in the direction of greater problems for cases excluded from the analysis.

\section{Measures}

Outcome: Child disruptive problem behaviors. The measure of child disruptive problem behaviors at each time point was constructed with eight items extracted from the Behavior Problems Index (BPI; Baker \& Mott, 1989) administered at 24 and 30 months, the Child Behavior Checklist/2-3 (CBCL/2-3; Achenbach, 1992) administered at 36 months, and the CBCL/4-18 (Achenbach, 1992) administered at 54 months. The BPI is a shortened behavior checklist developed for the National

1. The proportion of cases used in the analyses would be slightly higher if cases involving miscarriage, stillbirth, and adoption at birth were removed from the denominator.
Table 2. Correlations and means for disruptive behaviors at 24, 30, 36, and 54 months

\begin{tabular}{lcccc}
\hline \hline & \multicolumn{4}{c}{ Disruptive Behaviors } \\
\cline { 2 - 5 } $\begin{array}{l}\text { Disruptive } \\
\text { Behaviors }\end{array}$ & $\begin{array}{c}24 \\
\text { Months }\end{array}$ & $\begin{array}{c}30 \\
\text { Months }\end{array}$ & $\begin{array}{c}36 \\
\text { Months }\end{array}$ & $\begin{array}{c}54 \\
\text { Months }\end{array}$ \\
\hline 24 Months & - & & & \\
30 Months & .531 & - & & \\
36 Months & .420 & .604 & - & \\
54 Months & .425 & .367 & .535 & - \\
Mean & 7.17 & 7.17 & 5.68 & 5.26 \\
$S D$ & 3.18 & 3.22 & 3.37 & 3.03 \\
$N$ & 212 & 214 & 210 & 181 \\
\hline \hline
\end{tabular}

$p<.001$ for all correlations.

Longitudinal Survey of Youth by drawing on earlier versions of the CBCL (Achenbach \& Edelbrock, 1981). Each of the eight items appears across the three measures, and collectively they reflect a range of disruptive behaviors: (a) disobedient; (b) destroys own things; (c) destroys other's things; (d) cannot concentrate; (e) cannot sit still, restless; (f) stubborn, irritable; (g) sudden changes in mood or feelings; and (h) temper tantrums. Mothers rated the child behaviors on a 3 -point scale $(0=$ never, 1 = sometimes true, $2=$ often true). The scale computed by summing the eight items demonstrated good internal consistency at each time point, with alpha reliabilities ranging from .75 to .80 . Means, standard deviations, and correlations for scores at each time point are presented in Table 2.

The disruptive behavior scale was composed of the eight available items that load on the three factors of disruptive behavior that were theoretically derived and empirically validated in a study of 6-year-old children by Stormshak and colleagues (Stormshak, Bierman, \& Conduct Problems Prevention Research Group, 1998). Their oppositional, aggressive, and hyperactive factors based on CBCL items correspond to the oppositional defiant disorder, conduct disorder, and attention-deficit/hyperactivity disorder patterns of disruptive behavior in the DSM-IV. In the present study, however, making distinctions between oppositional, aggressive, and 
hyperactive items did not seem warranted given the small number of items available and because these distinctions have not been clearly conceptualized or empirically supported in research on younger children. For instance, the empirically derived CBCL/2-3 factor solution does not have an attention problem syndrome, and behaviors indicative of attention-deficit/ hyperactivity disorder at a later age load on the aggressive or destructive externalizing factors. Additionally, the second-order externalizing domain of the Infant-Toddler Social and Emotional Assessment for children between 12 and 36 months has both activity/impulsivity and aggression/defiance factors containing items very similar to those used in the present study (Carter, Briggs-Gowan, Jones, \& Little, 2003). Another consideration supporting creation of a general measure of disruptive behaviors is that the items load on the broadband externalizing scales of the CBCL/2-3, the CBCL/4-18, or both. Although most appear on the aggressive behavior syndrome scale of the CBCL/4-18, they are evenly mixed between aggressive and destructive subscales of the CBCL/2-3. Finally, the purpose of the study is to investigate early behavior trajectories that potentially signal the emergence of an early-starter pathway. Children displaying early co-occurring features of hyperactivityimpulsivity and aggression-noncompliance have more severe and persistent conduct problems than those with either type of problem alone (Campbell et al., 2000; Hinshaw et al., 1993).

Domain: Mother-infant attachment. Motherinfant attachment was assessed at 12 months using the Strange Situation (Ainsworth, Blehar, Waters, \& Wall, 1978). Videotapes of the interactive sequence were coded into insecureavoidant (A), secure (B), and insecureambivalent $(\mathrm{C})$ categories according to the procedures outlined by Ainsworth et al. (1978) and an insecure-disorganized/disoriented (D) category according to Main and Solomon (1990). The Strange Situation videos were independently coded by two individuals trained by the second author. Differences were resolved by consensus in consultation with the second author. Before conferencing, interrater agreement on the A, B, C, and D categories was $82 \%(\kappa=.74)$. In this sample, fewer than half the children $(42 \%)$ were judged to be securely attached. Of the insecurely attached children, the highest proportion was rated disorganized $(25 \%)$, followed by avoidant $(21 \%)$ and resistant (12\%). These proportions in each attachment category were essentially preserved among the 169 children in the final analysis sample $(\mathrm{B}=42 \%, \mathrm{D}=25 \%, \mathrm{~A}=$ $20 \%, \mathrm{C}=13 \%$ ). Descriptive data for attachment classifications and other domain-specific variables across time are presented in Table 3 .

Following Greenberg et al. (2001), the initial analyses examining interactions of attachment with contextual factors employed the dichotomous distinction between secure and insecure attachment. As noted previously, both insecure-avoidant and insecure-disorganized classifications have been associated with externalizing behaviors, and together these two categories make up the majority of insecure cases. Maintaining adequate cell sizes for examining attachment in combination with multiple other domains was a primary consideration for the main analyses. Subsequently, however, follow-up analyses were conducted to determine whether particular classifications of insecure attachment corresponded to a higher probability of problem behavior trajectories.

\section{Domain: Parental management and socialization.}

Unrealistic expectations about child behavior. Mothers' unrealistic expectations regarding child behavior were assessed at 12 and 36 months with 25 dichotomous items from the Parent Opinion Questionnaire (POQ; Azar, Robinson, Hekimian, \& Twentyman, 1984). The 25 items selected for this study from the original 80-item POQ were the ones relevant to toddlers and preschoolers, and this subset represented all content areas included in the larger instrument (e.g., self-care, responsibility, affection, behavior). The POQ score was derived by counting the number of unrealistic expectations. The POQ has good psychometric characteristics and has been shown to distinguish abusive from nonabusive parents 
Table 3. Descriptive statistics for domain-specific variables across time

\begin{tabular}{|c|c|c|c|c|c|c|}
\hline & 6 Months & 12 Months & 18 Months & 24 Months & 30 Months & 36 Months \\
\hline \multicolumn{7}{|l|}{ Mother-infant attachment } \\
\hline Avoidant & & $\begin{array}{l}20.6 \% \\
{[189]}\end{array}$ & & & & \\
\hline Secure & & $\begin{array}{l}41.8 \% \\
{[189]}\end{array}$ & & & & \\
\hline Resistant & & $\begin{array}{l}12.2 \% \\
\lceil 189]\end{array}$ & & & & \\
\hline Disorganized & & $\begin{array}{l}25.4 \% \\
{[189]}\end{array}$ & & & & \\
\hline \multicolumn{7}{|l|}{ Parenting } \\
\hline Unrealistic expectations & & $\begin{array}{c}5.45(3.32) \\
{[223]}\end{array}$ & & & & $\begin{array}{c}5.07(3.44) \\
{[221]}\end{array}$ \\
\hline Competence/satisfaction & & $\begin{array}{c}20.63(2.77) \\
{[224]}\end{array}$ & $\begin{array}{c}20.89(2.79) \\
{[217]}\end{array}$ & $\begin{array}{c}20.82(2.78) \\
{[211]}\end{array}$ & $\begin{array}{c}20.91(2.56) \\
{[214]}\end{array}$ & \\
\hline Warmth/affection & & $\begin{array}{c}4.98(2.50) \\
{[198]}\end{array}$ & $\begin{array}{c}5.53(2.52) \\
{[174]}\end{array}$ & & $\begin{array}{c}5.91(2.36) \\
{[164]}\end{array}$ & \\
\hline Negative control & & & & & $\begin{array}{c}9.13(6.28) \\
{[214]}\end{array}$ & $\begin{array}{l}9.61(6.82) \\
{[210]}\end{array}$ \\
\hline \multicolumn{7}{|l|}{ Family ecology } \\
\hline Depressive symptoms & & $\begin{array}{c}16.51(11.24) \\
{[241]}\end{array}$ & $\begin{array}{c}16.52(11.07) \\
{[239]}\end{array}$ & $\begin{array}{c}15.54(11.17) \\
{[239]}\end{array}$ & $\begin{array}{c}16.17(11.74) \\
{[242]}\end{array}$ & $\begin{array}{c}15.03(11.25) \\
{[243]}\end{array}$ \\
\hline Financial distress & & $\begin{array}{c}1.68(1.25) \\
{[241]}\end{array}$ & $\begin{array}{c}1.54(1.15) \\
{[239]}\end{array}$ & $\begin{array}{c}1.48(1.20) \\
{[239]}\end{array}$ & $\begin{array}{c}1.48(1.22) \\
{[242]}\end{array}$ & $\begin{array}{c}1.35(1.13) \\
{[243]}\end{array}$ \\
\hline Stressful life events & & $\begin{array}{c}2.29(1.69) \\
{[241]}\end{array}$ & $\begin{array}{c}2.17(1.54) \\
{[239]}\end{array}$ & $\begin{array}{c}2.18(1.68) \\
{[239]}\end{array}$ & $\begin{array}{c}2.34(1.85) \\
{[242]}\end{array}$ & $\begin{array}{c}2.09(1.62) \\
{[243]}\end{array}$ \\
\hline Antisocial behavior & & $\begin{array}{c}0.23(0.42) \\
{[241]}\end{array}$ & $\begin{array}{c}0.26(0.44) \\
{[239]}\end{array}$ & $\begin{array}{c}0.23(0.42) \\
{[239]}\end{array}$ & $\begin{array}{c}0.17(0.37) \\
{[242]}\end{array}$ & $\begin{array}{c}0.20(0.40) \\
{[243]}\end{array}$ \\
\hline \multicolumn{7}{|l|}{ Child characteristics } \\
\hline Gender (male) & $\begin{array}{c}55 \% \\
{[248]}\end{array}$ & & & & & \\
\hline Infant negativity & $\begin{array}{c}12.41(4.11) \\
{[233]}\end{array}$ & $\begin{array}{c}14.19(4.03) \\
{[215]}\end{array}$ & & & & \\
\hline
\end{tabular}

Note: Standard deviations are in parentheses and valid total numbers are in brackets. 
(Azar et al., 1984; Azar \& Rohrbeck, 1986). In the present sample, the modified version of the POQ had alpha coefficients of .73-.75.

Parenting role competence and satisfaction. Maternal feelings of competence and satisfaction in the parenting role were assessed with six items from Kalmuss, Davidson, and Cushman (1992): How good do you think you are at (a) providing for your child's physical needs (feeding, bathing, etc.), (b) soothing your child when he/she is fussy, (c) teaching your child, and (d) mothering? Additional items were (a) How happy do you feel as a mother? and (b) How satisfied do you feel as a mother? The scale created by summing these items is associated with successful transition to parenthood among new mothers (Kalmuss et al., 1992). The measure of competence/satisfaction, collected at 12, 18, 24, and 30 months, demonstrated good internal consistency $(\alpha=$ .75-.79).

Maternal warmth and affection. Motherchild dyads were observed in a teaching scenario at 12, 18, and 30 months using the Nursing Child Assessment Training Teaching Scale (Barnard, 1979). A subset of nine items indicating that the mother spontaneously or contingently directed warmth, affection, support, or praise toward the child was selected for this scale. Sample items included: parent laughs or smiles at child; parent gently pats, caresses, strokes, hugs, or kisses child; parent smiles and/or nods after child has performed better or more successfully; parent responds to the child's vocalizations with verbal response. Observers used dichotomous coding $(0=$ not observed, $1=$ observed $)$, and items were summed to create this index. The measure of warmth and affection had good internal consistency ( $\alpha=.80-.82)$.

Maternal negative control. At 30 and 36 months, the use of negative verbal and physical tactics to control child behavior was measured by a modified version of the Conflict Tactics Scale (CTS; Straus, 1974, 1979). As in previous research on parent-child interaction, the items were changed to designate the child, rather than a spouse, as the interactive partner.
Modified CTS scales have been used in numerous studies investigating parent-child interaction and have demonstrated concurrent and construct validity in research on child maltreatment (Straus \& Hamby, 1997). This selfreport scale consists of 11 items, including yelled, insulted, or swore at your child; threw, smashed, or kicked something; pushed, grabbed, or shoved your child; and spanked your child with something. Mothers reported on their behavior in the preceding 6 months on a 7 -point scale $(0=$ never, $6=$ almost every day). Items were summed to derive the CTS score, which had adequate internal consistency $(\alpha=.67-.70)$.

\section{Domain: Family ecology.}

Depressive symptoms. Maternal depressive symptoms were assessed at each interview with the Center for Epidemiologic Studies Depression Scale (CES-D; Radloff, 1977). The CES-D is a 20-item self-report scale designed to measure adult depressive symptomatology in the general population. The validity of the CES-D has been established with other selfreport measures and clinical ratings of depression in samples of young adults, adolescents, and adolescent mothers (Radloff, 1991; Roberts, Lewinsohn, \& Seeley, 1991; Wilcox, Field, Prodromidis, \& Scafidi, 1998). Items were summed to obtain scores for each of the five time points from 12 months to 36 months. For the present sample, alpha coefficients for the CES-D were above .90 for each time point.

Financial distress. The following four dichotomous items were summed to create an index of financial hardship: public assistance was primary means of financial support; serious money problems in the past 6 months; worries about having enough money fairly often or very often; and worries about meeting any basic needs (food for children, housing, medical care for self or for children) fairly often or very often. The financial distress index was computed for each of the interviews from 12 months to 36 months.

Stressful life events. An index of stressful life events experienced by the mother was cre- 
ated by summing the number of dichotomous items indicated on the Life Events Checklist (Coddington, 1972). One item from the Life Events Checklist was used in the Financial Distress measure above and excluded from this index, leaving 26 items covering difficulties in the mother's family of origin, deaths among family and friends, transitions, relationships, and other stresses. The index of stressful life events was computed for each interview from 12 to 36 months.

Maternal antisocial behavior. During each of the five interviews from 12 to 36 months, respondents were asked whether or not in the previous 6 months they had been involved with the justice system (in trouble with police, charged with a crime, jailed) or had engaged in certain delinquent behaviors (selling drugs, robbery, shoplifting, trespass, property damage, fighting). A dichotomous variable was created for each time point to indicate any affirmative responses to these items adapted from Bachman, O'Malley, and Johnston (1978).

\section{Domain: Child characteristics.}

Infant negativity. Maternal perception of infant negativity, reactivity, and poor selfregulation at 6 and 12 months of age was assessed using six items from the difficult child subscale of the Parent Stress Index-Short Form (PSI; Abidin, 1990). The items were the following: my child seems to cry or fuss more than most children; my child generally wakes up in a bad mood; I feel that my child is very moody and easily upset; my child reacts very strongly when something happens that my child does not like; my child gets upset easily at the smallest thing; my child's sleeping or eating schedule was much harder to establish than I expected. Mothers rated their infants on a 5 -point scale coded so that high scores indicate more negativity. Thus, infant negativity in this study resembles the dimension of temperament variously labeled negative emotionality, fussiness, irritability, proneness to distress, and negative affect (Rothbart \& Bates, 1998). Cronbach alphas for the summed scale ranged from .66 to .72 . Following previous studies classifying risk based on single variables (Greenberg et al., 2001), children with scores placing them in the top one third of the sample were classified into a high infant negativity group.

Cluster validation measures. Several conceptually related variables were selected to validate the results of cluster analyses within the domains described above. For the domain of parenting, these variables included measures of the home environment, parenting stress, and parental response to annoying child behavior. For the domain of family ecology, the validation variables included maternal self-esteem, social support, and exposure to violence.

Home environment. The Home Observation for the Measurement of the Environment (HOME; Caldwell \& Bradley, 1984) was conducted at 12 and 24 months, and total scores on the two assessments were averaged. The HOME assesses the parent's emotional and verbal responsiveness, avoidance of punishment, organization of the environment, provision of appropriate play material, involvement with child, and variety in daily stimulation.

Parenting stress. Two subscales of the PSI (Abidin, 1990) were combined for each time point from 12 to 36 months and then averaged across time points. The parental distress subscale taps the level of personal distress specifically related to the parenting role, and the parent-child dysfunctional interaction subscale assesses perceptions that the child is not meeting expectations or providing reinforcement to the mother, leading to feelings of dissatisfaction, rejection, or alienation in the relationship.

Annoyance and punishment vignettes. The 12-month interview presented mothers with 18 hypothetical vignettes (e.g., you give your infant a bottle and come back a few minutes later and see the top off the bottle and milk spilled on the rug) and asked them to rate on a 9-point scale first how much they would think that their child had intended to annoy them and then how much they would punish the child (Azar \& Twentyman, 1986). 
Maternal self-esteem. A measure of maternal self-esteem was created by averaging scores from assessments at 18 and 30 months using the Rosenberg self-esteem scale (Rosenberg, 1965).

Social support. To gauge the level of social support available, the mother was read a list of 12 people (e.g., partner, parents, siblings, friends, relatives, professionals) and asked to rate how much she could count on each person to help if she had a serious problem. The number of people on whom she could count "quite a bit" or "a great deal" was tallied to indicate the extent of high quality support available in times of adversity, and these counts were averaged across each time point from 12 to 36 months.

Exposure to violence. Items were adapted from previous research on exposure to community violence (Richters \& Saltzman, 1990). At each interview, respondents were asked whether they had been chased by gang members, beaten up, attacked with a knife, or shot in the preceding 6 months. Next they were asked whether a close friend or relative had experienced the same (or been killed). Finally, respondents were asked whether they had witnessed anyone else being threatened or attacked in these ways (or killed). The number of affirmative responses for each 6-month period was summed, and then scores were averaged across the time points.

\section{Within-domain analyses}

Problem behavior trajectory analysis. Growth mixture modeling (GMM) with latent variables was used to identify distinct classes of disruptive problem behavior trajectories $(\mathrm{Li}$, Duncan, Duncan, \& Acock, 2001; Muthén \& Muthén, 2000). The GMM analyses were conducted with the Mplus (Version 2.01) software program, which expands traditional latent variable modeling by incorporating both continuous and categorical latent variables (Muthén, 2001; Muthén \& Muthén, 1998). Based on a finite mixture modeling framework, a categorical latent variable reflects the partitioning of a total population into homogeneous groups whose unobserved membership must be inferred from the data ( $\mathrm{Li}$ et al., 2001). In GMM, this person-oriented approach models heterogeneity in development by using a latent categorical variable to represent a mixture of subpopulations that have distinctive latent growth curve trajectories (Muthén \& Muthén, 2000).

GMM is based on conventional growth curve modeling in which longitudinal data on an outcome variable is related to time or age with random coefficients estimated as continuous latent growth factors, that is, intercept and slope (Duncan, Duncan, Strycker, Li, \& Alpert, 1999). Conventional growth modeling assumes a single population and estimates a mean growth curve with individual variation reflected in estimated growth factor variances. However, GMM tests whether the population is composed of discrete trajectory classes, estimating means and variances for the growth factors of each class (Muthén \& Muthén, 2000). Evidence for different trajectory classes exists when models with two or more latent classes provide a better fit to the data. Classification of individuals is based on estimated posterior probabilities that indicate the likelihood of a particular case belonging to each trajectory class.

GMMs are estimated with maximumlikelihood procedures, and model fit is indicated by the log-likelihood value. The Bayesian information criterion (BIC) is recommended to compare nonnested models with different numbers of latent classes for the best fit to the data (Raftery, 1995). It balances maximization of the likelihood function against parsimony on the number of parameters and is calculated for each model as BIC = $-2 \log (\mathrm{L})+k \times \ln (n)$, where $\log (\mathrm{L})$ is $\log$ likelihood, $k$ is the number of parameters, and $n$ is the sample size. A lower BIC value signifies a better fitting model. Other considerations in selecting the preferred solution include (a) clearly distinguishable latent classes based on classification quality with posterior probabilities; and (b) practical utility of the solution, for example, dissimilar trajectories, adequate class sizes, and theoretically interpretable (Muthén \& Muthén, 2000). 


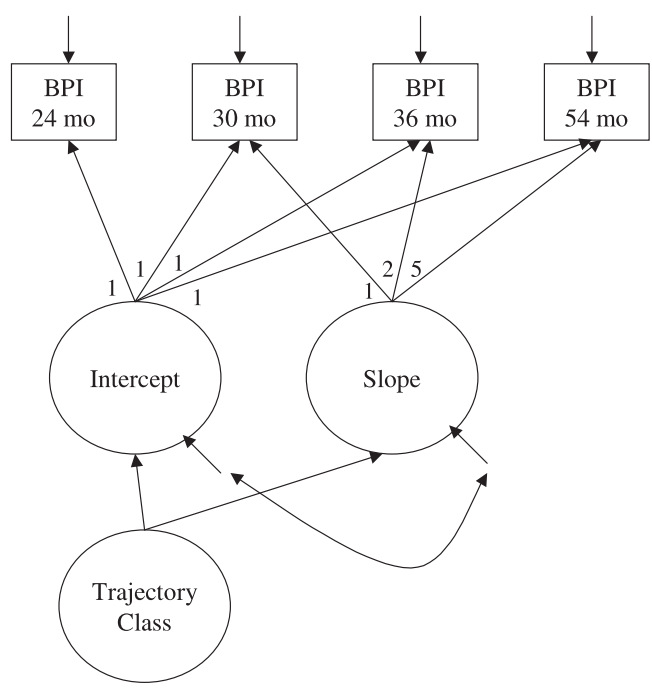

Figure 1. The growth mixture model.

In the present study, latent trajectory classes were determined from the intercept and slope factors of the latent growth curve model as shown in Figure 1. The latent growth curve portion of the model specified a linear trajectory for disruptive behavior scores across the four time points. Loadings on the intercept factor were set to 1 because the initial status is constant across time, while loadings for the slope factor were fixed at 1,2 , and 5 to reflect 6-month intervals from the intercept at 24 months. For the latent class portion of the model, the number of trajectory classes was designated, and starting values were supplied to initiate maximum-likelihood estimation.

Cluster analysis of parenting and family ecology domains. The objective for the withindomain portion of the analysis was to categorize children into groups reflecting meaningful differences in their experience in the domains of parenting and family ecology. Cluster analysis was used to identify distinctive groups because the purpose was to represent the general, contextual features of each domain rather than to isolate single, unidimensional constructs. The analyses employed a two-step procedure: hierarchical clustering using Ward's method followed by iterative cluster partitioning with a K-means analysis. Ward's method is a hierarchical, agglomerative technique that combines cases so that the variance of the squared Euclidean distance within clusters is minimized (Aldenderfer \& Blashfield, 1984; Anderberg, 1973). Because determination of the optimal number of clusters relies upon a combination of empirical and practical considerations, the retention of clusters was based on dendrograms depicting the agglomeration schedule as well as the size, distinctiveness, and interpretability of the groupings.

A drawback of hierarchical clustering techniques is that cases remain in a particular cluster once assigned, regardless of how the cluster may change with the addition of subsequent cases. The use of K-means analysis allows for adjustments in cluster membership. Beginning with an initial partitioning of the data into clusters, the K-means procedure computes cluster centroids and then passes through the data assigning each case to the cluster with the nearest centroid (Aldenderfer \& Blashfield, 1984; Anderberg, 1973). The process is repeated until no reassignments are made. A problem with iterative partitioning methods is high sensitivity to poor starting values (Aldenderfer \& Blashfield, 1984). In this study, the Ward's method solution provided the "seed" values for the initial cluster centers. Theoretically, using the two-step combination of clustering approaches preserves the integrity of the solution derived from Ward's method but also enhances the solution through adjustments in cluster membership during the K-means procedure (Huberty, DiStefano, \& Kamphaus, 1997).

Before undertaking the two-step procedure, each variable representing a given domain was averaged across time points to provide a reliable measure of that variable over time. Because the measures had varying metrics, all were standardized prior to cluster analysis (Aldenderfer \& Blashfield, 1984). Each variable was standardized using all data available from the entire sample of adolescent mothers, and then the cases with complete data on the relevant variables were selected for cluster analysis. 


\section{Cross-domain analyses}

The second stage of the analysis determined whether individuals with specific combinations of attachment organization and environmental context were more or less likely to belong to a certain behavior trajectory class. Because each individual was assigned a category for each domain as well as for the behavioral trajectory, individuals could be designated to particular cells in a cross-tabulated contingency table. Thus, the objective was to identify cells with an observed frequency greater than would be expected by chance (a type) or smaller than expected by chance (an antitype; Bergman \& Magnusson, 1997). In essence, each cell suggests a separate developmental pattern: particular aspects of early experience linked to later behavior.

The chi-square test of independence does not evaluate observed single cell frequencies relative to expected frequencies. Furthermore, chi-square and log-linear methods examine statistical correspondence between categorical variables based on large-sample, asymptotic distributions, and are inaccurate and nonconservative for small expected cell values (Agresti, 1990; Bergman \& El-Khouri, 1987). To address these concerns, the present study used the SLEIPNER software package (Bergman \& El-Khouri, 1998) for computing exact one-tailed probabilities of observed cell frequencies based on Fisher's exact test of a $2 \times 2$ table. Under the null hypothesis of independence, every possible arrangement of $N$ cases is equally probable, observed frequencies follow the hypergeometric distribution obtained with fixed margins, and the $p$ value is the sum of probabilities for outcomes with frequencies at least as extreme as the observed value (Agresti, 1990; Bergman \& ElKhouri, 1987).

Following the approach in a person-oriented study by Radke-Yarrow and colleagues (1995), the analytic strategy was to examine progressively more homogeneous subgroups by increasing the number of domains considered in a sequential fashion. Consequently, each successive round of the analysis provided a greater degree of specificity regarding individuals by producing increasingly differentiated cells in contingency tables. The tables constructed in this manner represented increasingly complex areas of overlapping risks shown in the Greenberg model Venn diagram (for a diagram, see Greenberg, 1999, or Greenberg et al., 2001). Furthermore, moving from single domains to multiple domains permitted examination of attachment in context.

Investigating patterns of overlap between multiple domains quickly results in a large number of cells, with multiple statistical tests raising the possibility of chance findings. However, this concern is mitigated somewhat by several conceptual and methodological considerations. First, the more numerous cells obtained with more complex combinations of domains in subsequent rounds contained the same individuals in the earlier contingency tables. Thus, subsequent tests should not be interpreted as independent tests but as nested tests, so results do not necessarily indicate "new" findings but more precise findings. Second, because the number of cases remained the same, the larger number of cells with expansion of contingency tables was offset by limited statistical power due to smaller cell sizes. Third, as noted above, the exact test is a conservative method, and the type and antitype designations were assigned to patterns with less than .05 probability of chance occurrence. Fourth, as Bronfenbrenner and Morris (1998) point out, ecological research to reveal more precise patterns of interdependency in the data typically has a greater risk of failing to detect important interactions than of finding too many.

\section{Results}

\section{Within-domain results}

Problem behavior trajectory analysis. For GMM, all cases with disruptive behavior scores for at least three of the four time points were used in the analysis $(n=210)$. Based on the work of Little and Rubin (1987), the Mplus program includes features for maximum likelihood estimation with data missing at random (Muthén \& Muthén, 1998; Schafer \& Graham, 2002). Cases missing data met the criteria for data missing at random, and were considered 


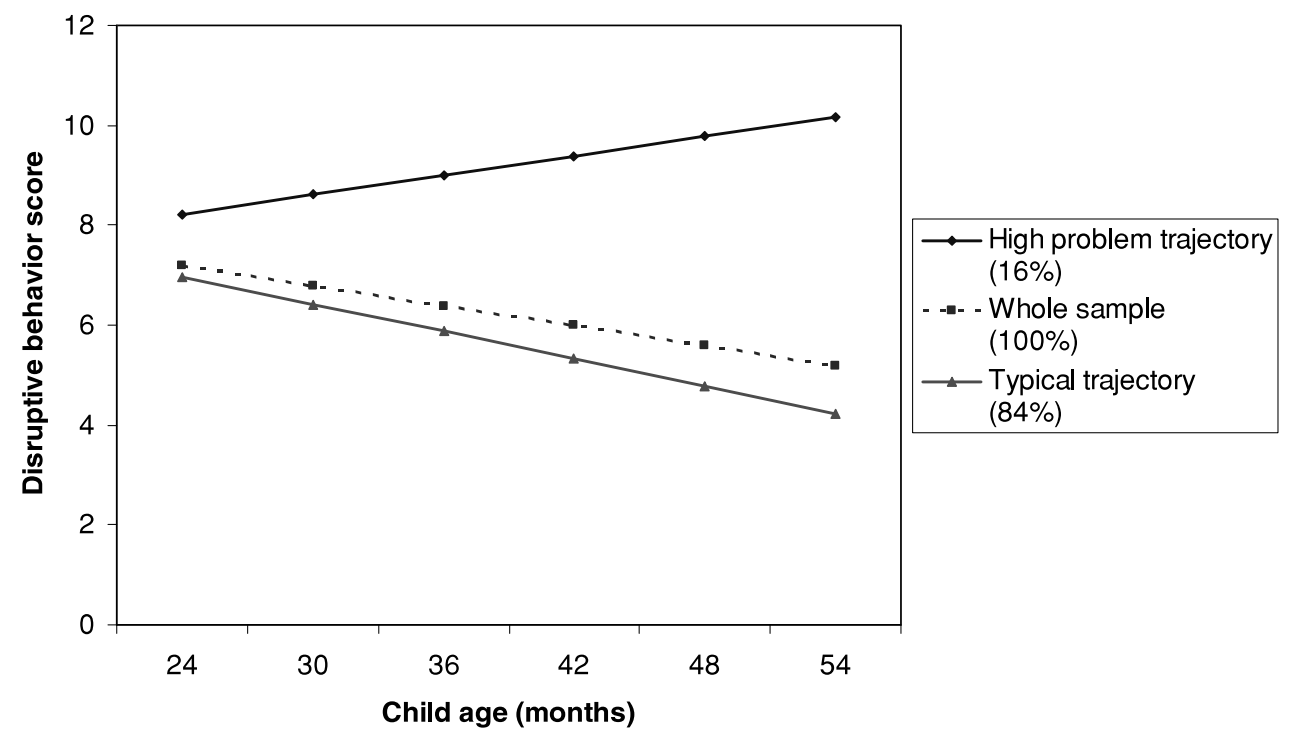

Figure 2. Problem behavior trajectories of the whole sample and two latent classes.

appropriate for analysis (Schafer \& Graham, 2002). The final time point, at 54 months, had the highest level of missingness due to the reduction in sample size at that phase of the study, but the proportion of data coverage was .83 or above for all covariances (minimum allowable $=.10$ ).

The first step in distinguishing the best fitting model was to conduct a traditional growth curve analysis on the entire sample (i.e., a one-class model). This yielded a single estimated trajectory for disruptive behavior problems with a 24-month intercept of 7.19 and a statistically significant downward slope of $-0.40(t=8.5$; see Figure 2). This decline in the average level of problem behaviors is consistent with previous longitudinal analyses of disruptive behavior trends over the preschool years (Spieker et al., 1999). Next, several twoclass models with different starting values were estimated because any given solution may reflect local maxima. The various two-class models yielded two different solutions, one of which had a better fit to the data than the single class model based on a substantial improvement of the BIC statistic. The procedure was continued by estimating several threeclass models with a range of starting values. All three-class models converged to the same solution, which had a worse BIC statistic than the two-class solution but approximately equal to the single class solution. Finally, multiple four-class models were estimated, yielding one solution with a BIC statistic worse than all previous models. The BIC values for the solutions with differing numbers of trajectory classes were as follows: one-class model = 3972.5, two-class models $=3963.2$ and 3986.0, three-class model $=3972.3$, and four-class model $=3990.9$. The two-class solution with $\mathrm{BIC}=3963.2$ also compared favorably in terms of other model selection criteria, and therefore it was deemed the optimal solution. ${ }^{2}$

The trajectories of the two-class solution are shown in Figure 2. The majority of cases (84\%) followed a course very similar to the overall sample trajectory presented above, with a 24-month intercept for disruptive behaviors of 6.97 and a significant downward slope of $-0.55(t=9.6)$. On the other hand, a rela-

2. For mixture models, Mplus (Version 2.01) does not provide tests of model fit other than the log-likelihood and information criteria (e.g., BIC). The wholesample reference model had relatively poor fit indices (standardized root mean square residual $=.094$, root mean square error of approximation $=.202$ ). This result suggests that a single class model is not adequate and that modeling more than one class is warranted. 
Table 4. Comparison of CBCL internalizing and externalizing scores by trajectory class membership

\begin{tabular}{cccc}
\hline \hline & $\begin{array}{c}\text { Problem } \\
\text { Trajectory }\end{array}$ & $\begin{array}{c}\text { Typical } \\
\text { Trajectory }\end{array}$ & $\begin{array}{c}\text { Comparison } \\
\text { Statistic }\end{array}$ \\
\hline Internalizing behavior & & & \\
36 Months (CBCL 2-3) & & & \\
Mean $T$ score $(S D)$ & $56.4(9.5)$ & $52.3(9.2)$ & $t=2.0, p=.046$ \\
Above clinical cutoff $(T>$ 63) & $30.4 \%$ & $11.7 \%$ & $\chi^{2}=5.8, p=.016$ \\
54 Months (CBCL 4-18) & $57.2(9.3)$ & $48.9(7.7)$ & $t=5.2, p<.001$ \\
Mean $T$ score $(S D)$ & $22.7 \%$ & $4.1 \%$ & $\chi^{2}=10.7, p=.001$ \\
Above clinical cutoff $(T>63)$ & & & \\
Externalizing behavior & & $52.1(9.0)$ & $t=4.6, p<.001$ \\
36 Months (CBCL 2-3) & $39.1 \%$ & $8.6 \%$ & $\chi^{2}=17.2, p<.001$ \\
Mean $T$ score $(S D)$ & & & $t=13.8, p<.001$ \\
Above clinical cutoff $(T>63)$ & $70.2(4.6)$ & $54.2(7.4)$ & $\chi^{2}=67.0, p<.001$ \\
54 Months (CBCL 4-18) & $90.9 \%$ & $12.4 \%$ & \\
Mean $T$ score $(S D)$ & Above clinical cutoff $(T>$ 63) & &
\end{tabular}

Note: The $T$ scores normalized on a representative, nonclinical sample with mean $=50$ and $S D=10$.

${ }^{a}$ Differing numbers of CBCL scores were available at 36 and 54 months: problem trajectory class: 36 months $(N=23)$, 54 months $(N=22)$; typical trajectory class: 36 months $(N=162), 54$ months $(N=145)$.

tively small proportion of cases $(16 \%)$ exhibited a very different trajectory. This group was characterized by a higher 24-month intercept (8.22) and a statistically significant upward slope of $+0.39(t=2.5)$. This solution, which indicated a small but distinct group of children with more severe and escalating problem behaviors, is consistent with the type of extreme trajectories expected of early-starter or life-course persistent patterns.

Individual cases were classified into a trajectory class based on a posterior probability for membership in that class of .75 or greater (suggesting a case would be correctly classified at least three out of four times). This criteria resulted in the loss of 16 cases $(8 \%)$ that were situated on the boundary between classes and had indeterminate group membership. ${ }^{3}$ Of the remaining 194 cases, $88 \%$ were classified

3. Average posterior probabilities $(\mathrm{Pp})$ for the typical trajectory class (class 1 ) and the high problem trajectory (class 2) when all subjects were classified based on most likely group membership (i.e., class probability $>.50$ ) were as follows: typical trajectory (mean class $1 \mathrm{Pp}=.956$, mean class $2 \mathrm{Pp}=.044)$; high problem trajectory (mean class $1 \mathrm{Pp}=.165$, mean class $2 \mathrm{Pp}=.835$ ). Given the theoretical and clinical implications of the early-starter and life-course persistent pathways, the emphasis when classifying cases with the typical disruptive behavior trajectory, and $12 \%$ displayed the high problem behavior trajectory.

To examine how well patterns of child problem behaviors were distinguished by the trajectory classifications, the two groups were compared on their CBCL internalizing and externalizing scores at 36 and 54 months. As shown in Table 4 , the mean $T$ scores and the percentages above clinical cutoffs were substantially greater for the high problem trajectory class for both internalizing and externalizing behaviors at each time point. Differences between trajectory classes on internalizing behaviors were expected, given high correlations between internalizing and exter-

was on avoiding "false positives." Thus, specificity was prioritized over sensitivity, and the more stringent criteria for classification based on posterior probabilities over .75 was imposed. After classification according to these criteria, the average posterior probabilities by class were improved, particularly for the smaller high problem trajectory class: typical trajectory (mean class $1 \mathrm{Pp}=.966$, mean class $2 \mathrm{Pp}=.034)$; high problem trajectory (mean class $1 \mathrm{Pp}=.076$, mean class $2 \mathrm{Pp}=.924)$. The indeterminate status of the 16 cases removed from the analyses is demonstrated by their average posterior probabilities (mean class $1 \mathrm{Pp}=$ .480 , mean class $2 \mathrm{Pp}=.520$ ). 


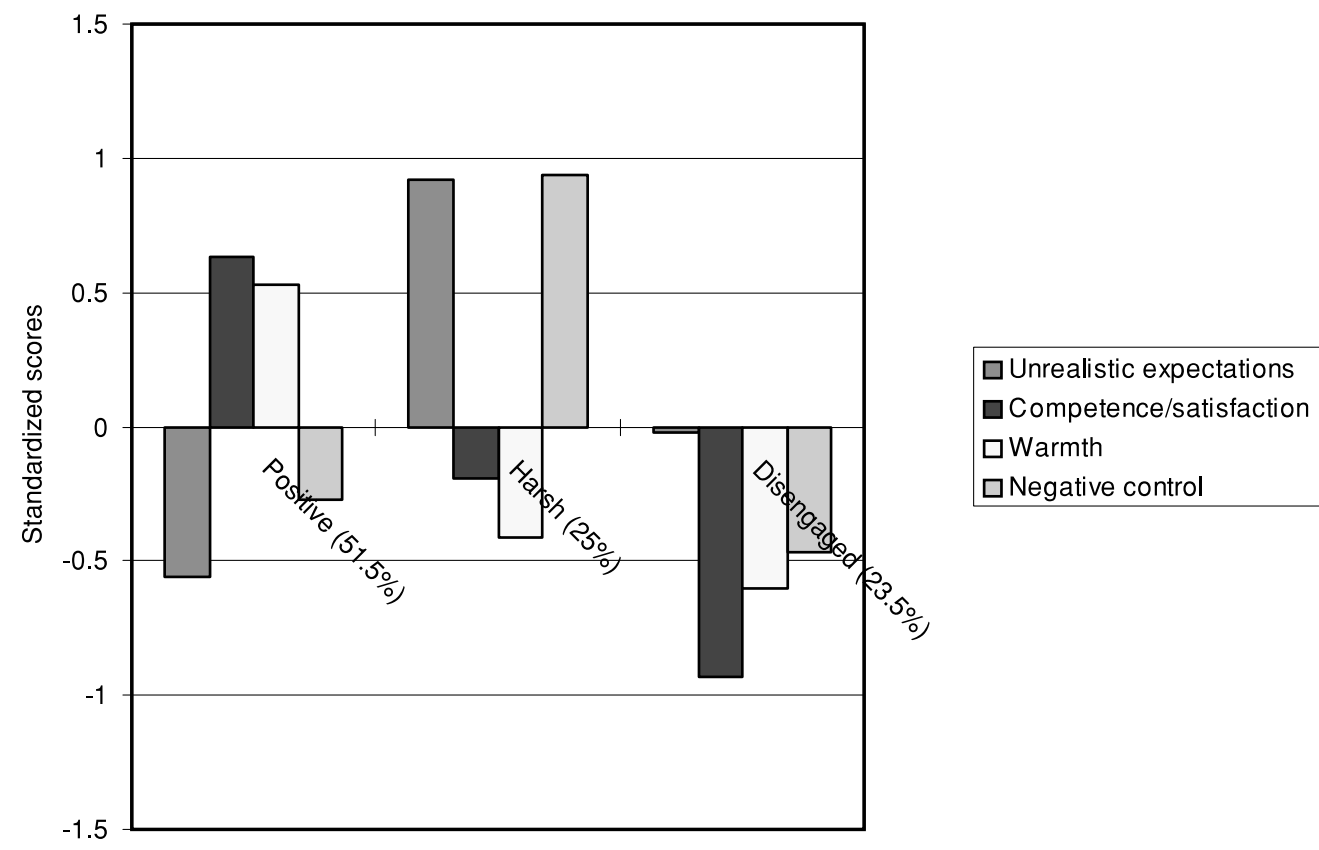

Figure 3. Profiles of three parenting cluster groups.

nalizing scores on the CBCL and other evidence of comorbidity for mood disorders and conduct problems among children (Achenbach, 1991, 1992; Hinshaw et al., 1993; Loeber \& Keenan, 1994). Nevertheless, the discrimination by trajectory class of externalizing behaviors at both time points was superior to the discrimination of internalizing behaviors at either time point, based on the magnitudes of mean between-group differences and the relative improvement over chance in classifying clinical-level cases. Reflecting the divergent slopes of the two trajectories, the between-group distinctions on both internalizing and externalizing behaviors increased from 36 months to 54 months. With respect to the best criterion measure, externalizing behaviors at 54 months, $91 \%$ of children in the high problem trajectory scored above the clinical cutoff compared to $12 \%$ of children in the typical trajectory group. Distinguishing clinical-level externalizing status at 54 months by trajectory class showed a high level of specificity (.98) and a modest level of sensitivity (.53).

Cluster analysis of parenting domain. In this study, the objective was to identify a few dis- tinctive parenting contexts in terms of risk exposure based on several dimensions of the parenting domain: unrealistic expectations of children, parenting competence/satisfaction, emotional warmth, and negative control strategies. The cluster analytic procedures outlined above were applied to the 204 cases with complete data on these four variables averaged over time. Based on the Ward method dendrogram and considerations of cluster size and interpretability, three clusters for the parenting domain were retained. The cluster profiles on the standardized variables are presented in Figure 3.

The largest cluster, containing slightly over half the cases $(51.5 \%)$, was interpreted as a "positive parenting" group. As the profile for this group indicates, these mothers were characterized by realistic expectations for child behavior and care, feelings of competence and satisfaction in the parenting role, displays of emotional warmth, and low reliance on negative control. The next group, with a quarter of the cases, suggested a "harsh" parenting context. Relative to the sample means, this profile indicated parents with highly unrealistic expectations of children, somewhat lower levels of role competence, less emotional warmth, 


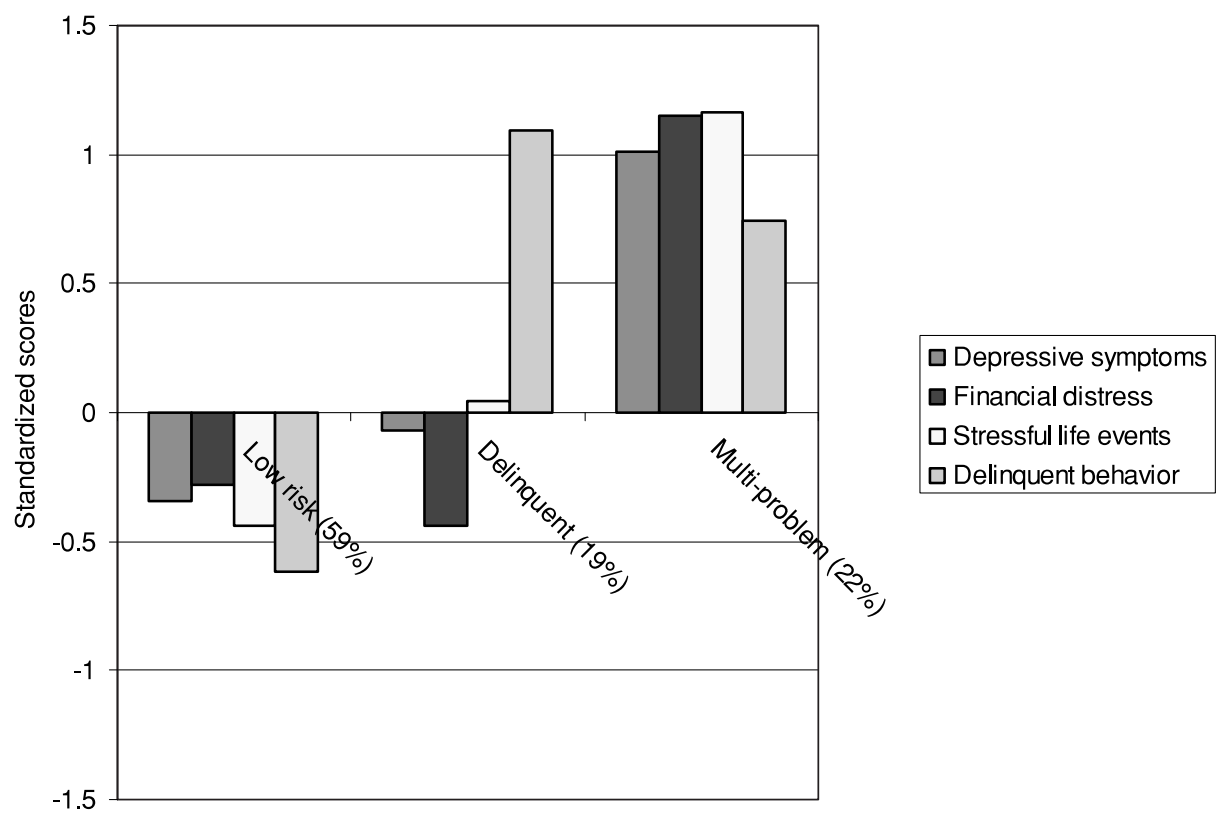

Figure 4. Profiles of three family ecology clusters.

and heavy reliance on negative control strategies. The final group $(23.5 \%)$ presented more of a challenge for interpretation, but the profile suggested a group of parents less engaged in parenting. This "disengaged" group was characterized by very low competence/satisfaction in the parenting role, lack of emotional warmth, and little use of negative control strategies.

The validity of the cluster groupings was assessed by conducting a multivariate analysis of variance (MANOVA) comparing cluster group differences on independent measures that also conceptually represent the parenting domain: the HOME environment, the PSI parenting stress subscales, and the vignettes assessing the parent's tendency to become annoyed by child behavior and punish the child. Significant overall group differences were found in the MANOVA analysis $(F=10.9$; $d f=8,360 ; p<.001)$. Univariate post hoc comparisons employing Tukey honestly significant difference (HSD) revealed a consistent pattern across all the validating variables. The positive parenting group was significantly different from the two high-risk groups on each variable, but no statistically significant differences were observed between the two high-risk groups. These results suggested a clear and meaningful distinction between high- and low-risk groups but did not support finer differentiation between the two higher risk groups. For this reason, the two higher risk groups were combined.

Cluster analysis of family ecology domain. As with the parenting domain, the objective was to categorize families into groups reflecting meaningful differences in the nature of the family environment. The variables representing diverse dimensions of the child's family ecology were maternal depressive symptoms, financial distress, stressful life events, and maternal delinquent behavior. The first three measures were averaged over the time points, and the fourth measure was calculated as the proportion of completed interviews in which delinquency was reported. The 249 cases with complete data were used for clustering. Based on the Ward method dendrogram and considerations of cluster size and interpretability, three family ecology clusters were retained. Profiles for the three groups are shown in Figure 4.

A "low-risk" group containing 59\% of the cases was characterized by relatively low levels 
Table 5. Single domain associations with problem trajectory

\begin{tabular}{|c|c|c|c|c|c|}
\hline & \multicolumn{2}{|c|}{$\begin{array}{c}\text { Trajectory } \\
\left(F_{\mathrm{O}} / F_{\mathrm{E}}\right)\end{array}$} & \multirow{2}{*}{$\begin{array}{c}\text { Exact } \\
\text { Probability }\end{array}$} & \multirow{2}{*}{$\begin{array}{l}\text { Problem } \\
\text { Trajectory } \\
(\%)\end{array}$} & \multirow[b]{2}{*}{ Result } \\
\hline & Problem & Typical & & & \\
\hline \multicolumn{6}{|l|}{ Attachment only } \\
\hline Secure & $6 / 9.2$ & $65 / 61.8$ & .101 & 8.5 & \\
\hline Insecure & $16 / 12.8$ & $82 / 85.2$ & .101 & 16.3 & \\
\hline \multicolumn{6}{|l|}{ Parenting only } \\
\hline Positive & $7 / 10.9$ & $76 / 72.1$ & .061 & 8.4 & \\
\hline High risk & $15 / 11.1$ & $70 / 73.9$ & .061 & 17.6 & \\
\hline \multicolumn{6}{|c|}{ Family ecology only } \\
\hline Low risk & $13 / 14.1$ & $95 / 93.9$ & .389 & 12.0 & \\
\hline Delinquent & 3/3.9 & $27 / 26.1$ & .423 & 10.0 & \\
\hline Multiproblem & $6 / 4.0$ & $25 / 27.0$ & .190 & 19.4 & \\
\hline \multicolumn{6}{|l|}{ Infant negativity } \\
\hline Low & $10 / 15.0$ & $105 / 100.0$ & .016 & 8.7 & Antitype \\
\hline High & $12 / 7.0$ & $42 / 47.0$ & .016 & 22.2 & Type \\
\hline \multicolumn{6}{|l|}{ Child gender } \\
\hline Female & $8 / 9.2$ & $63 / 61.8$ & .369 & 11.3 & \\
\hline Male & $14 / 12.8$ & $84 / 85.2$ & .369 & 14.3 & \\
\hline
\end{tabular}

of maternal depressive symptoms, financial distress, stressful life events, and delinquency. A "delinquent" group comprising 19\% of the sample featured average levels of depressive symptoms and life events, little financial distress, but highly elevated rates of delinquency. A third "multiproblem" group, with $22 \%$ of the cases, exhibited extremely high levels of maternal depressive symptoms, financial distress, stressful life events, and delinquency.

The validity of these clusters was assessed by conducting MANOVA comparing group differences on conceptually related variables: maternal self-esteem, number of individuals providing quality social support to the mother, and maternal exposure to violence. Significant overall group differences were found in the MANOVA analysis $(F=14.3 ; d f=6,478$; $p<.001)$. Univariate post hoc comparisons using Tukey HSD revealed a pattern supporting the distinctive characteristics of each cluster group. For maternal self-esteem, the multiproblem group was significantly lower than the other two groups. With respect to social support, the multiproblem group was significantly lower than the low-risk group but not different from "delinquent" group. All three groups differed significantly on exposure to violence, with multiproblem having the greatest and low risk the least exposure. Based on this evidence, the three clusters were retained as separate groups.

\section{Cross-domain results}

Descriptive results. Of the 22 children exhibiting the high problem behavior trajectory, the majority were insecurely attached to their mothers at 12 months (73\%), exposed to highrisk parenting between the period from 12 to 36 months $(68 \%)$, male $(64 \%)$, and rated by their mothers as having high levels of negativity as infants $(55 \%)$. A substantial proportion also lived in a high-risk, multiproblem family environment $(27 \%)$.

Single-domain results. Single domains were examined with reference to the trajectories before moving to cross-domain analyses. Results for each contingency table are reported in Table 5. This table presents the observed and expected frequencies for each cell, the exact probability of the observed frequency being greater or less than the expected frequency, and the percentage of children in the particular risk category who exhibit the high problem trajectory. Patterns identified as sta- 
tistically significant types and antitypes also are indicated.

Attachment only. The proportion of insecurely attached children exhibiting the high problem trajectory $(16.3 \%)$ was nearly double the rate for securely attached children $(8.5 \%)$. However, the number of insecurely attached children displaying the problem trajectory did not exceed the expected frequency by enough to reach the criterion for statistical significance $($ Observed $[\mathrm{O}]=16$, Expected $[\mathrm{E}]=$ $12.8, p=.101)$.

Parental management and socialization only. Children raised by mothers in the highrisk parenting category were more likely to develop the problem trajectory $(17.6 \%)$ than those with mothers in the positive parenting category $(8.4 \%)$, but this differential was not statistically significant.

Family ecology only. The likelihood of a problem trajectory was higher for children in multiproblem families (19.4\%) than their counterparts in families characterized by parental delinquency $(10.0 \%)$ or low environmental risk (12.0\%), but this difference was not statistically significant.

Infant negativity only. Children rated with high maternal ratings of infant negativity at 6 and 12 months were significantly more likely than expected by chance to exhibit the problem trajectory $(\mathrm{O}=12, \mathrm{E}=7.0, p=.016)$. Conversely, all other children were significantly less likely to have the problem trajectory $(\mathrm{O}=10, \mathrm{E}=15.0, p=.016)$.

Child gender only. More boys than girls were classified into the problem trajectory group, but gender was not statistically associated with behavior trajectory.

Two-domain results. Given the large number of permutations possible within the Greenberg model, the goal was to examine the role of attachment in context, and only crossdomain combinations involving attachment were investigated. Attachment security was evaluated in conjunction with each of the other domains one at a time to examine potential protective effects in different contexts. Analyses were necessarily limited to cases with categorical data for each domain being examined, resulting in the loss of some cases to listwise deletion depending upon the particular combination.

The results appearing in Table 6 are organized first by level of risk in the designated domain and then by attachment status to permit easy comparison of securely and insecurely attached children within a particular context. In addition, the risk combinations progress from secure attachment in low-risk circumstances to insecure attachment in high-risk situations. Given the hypotheses, an uneven stepwise progression with greater probability of the trajectory as the table descends would be anticipated.

Attachment with parental management and socialization. Only 1 of the 37 securely attached children experiencing positive parenting was also in the clinical problem trajectory group, signifying a statistically significant antitype $(\mathrm{O}=1, \mathrm{E}=4.8, p=.023)$. Thus, attachment security plays a role in identifying a certain group of children who have a particularly low risk of developing the problem trajectory. In comparison, approximately one out of five insecurely attached children experiencing high-risk parenting exhibited the problem trajectory, a rate that was almost statistically significant as a type $(\mathrm{O}=10, \mathrm{E}=6.7, p=$ .083). The number of children with one or the other of the two risk factors was at or very near the prevalence for the problem trajectory in the overall sample.

Attachment with family ecology. One quarter of the insecurely attached children in multiproblem family environments demonstrated the problem trajectory. Although not designated a type, this is twice the likelihood expected by chance $(\mathrm{O}=5, \mathrm{E}=2.5, p=.078)$. For interpreting this result, an important point is that securely attached children exposed to the same type of distressed environment were no more likely than chance to be in the problem trajectory group $(\mathrm{O}=1, \mathrm{E}=1.6, p=.519)$. Within similar environmental contexts, attachment 
Table 6. Two domain patterns associated with problem trajectory

\begin{tabular}{|c|c|c|c|c|c|}
\hline & \multicolumn{2}{|c|}{$\begin{array}{c}\text { Trajectory } \\
\left(F_{\mathrm{O}} / F_{\mathrm{E}}\right)\end{array}$} & \multirow{2}{*}{$\begin{array}{c}\text { Exact } \\
\text { Probability }\end{array}$} & \multirow{2}{*}{$\begin{array}{l}\text { Problem } \\
\text { Trajectory } \\
(\%)\end{array}$} & \multirow[b]{2}{*}{ Result } \\
\hline & Problem & Typical & & & \\
\hline \multicolumn{6}{|l|}{ Parenting and attachment } \\
\hline Pos. par./secure & $1 / 4.8$ & $36 / 32.2$ & .023 & 2.7 & Antitype \\
\hline Pos. par./insecure & $6 / 6.0$ & $40 / 40.0$ & 607 & 13.0 & \\
\hline High-risk par./secure & $5 / 4.5$ & $29 / 29.5$ & .472 & 14.7 & \\
\hline High-risk par./insecure & $10 / 6.7$ & $41 / 44.3$ & .083 & 19.6 & \\
\hline \multicolumn{6}{|l|}{ Family ecology and attachment } \\
\hline Low-risk ecol./secure & $4 / 5.9$ & $41 / 39.1$ & .247 & 8.9 & \\
\hline Low-risk ecol./insecure & $9 / 8.2$ & $54 / 54.8$ & .438 & 14.3 & \\
\hline Delinq. ecol./secure & $1 / 1.8$ & $13 / 12.2$ & .430 & 7.1 & \\
\hline Delinq. ecol./insecure & $2 / 2.1$ & $14 / 13.9$ & .654 & 12.5 & \\
\hline Multiprob. ecol./secure & $1 / 1.6$ & $11 / 10.4$ & .519 & 8.3 & \\
\hline Multiprob. ecol./insecure & $5 / 2.5$ & $14 / 16.5$ & .078 & 26.3 & \\
\hline \multicolumn{6}{|c|}{ Infant negativity and attachment } \\
\hline Low neg./secure & $3 / 6.1$ & $44 / 40.9$ & .086 & 6.4 & \\
\hline Low neg./insecure & $7 / 8.9$ & $61 / 59.1$ & .267 & 10.3 & \\
\hline High neg./secure & $3 / 3.1$ & $21 / 20.9$ & .618 & 12.5 & \\
\hline High neg./insecure & $9 / 3.9$ & $21 / 26.1$ & .005 & 30.0 & Type \\
\hline \multicolumn{6}{|l|}{ Child gender and attachment } \\
\hline Female/secure & $2 / 3.6$ & $26 / 24.4$ & .250 & 7.1 & \\
\hline Female/insecure & $6 / 5.6$ & $37 / 37.4$ & .507 & 14.0 & \\
\hline Male/secure & $4 / 5.6$ & $39 / 37.4$ & .291 & 9.3 & \\
\hline Male/insecure & $10 / 7.2$ & $45 / 47.8$ & .128 & 18.2 & \\
\hline
\end{tabular}

security appears to distinguish the likelihood of a problem trajectory.

Attachment with infant negativity. Insecurely attached children rated high on infant negativity were significantly more likely to belong to the problem trajectory group than expected by chance $(\mathrm{O}=9, \mathrm{E}=3.9, p=$ $.005)$, while securely attached children rated with similar levels of infant negativity were $\operatorname{not}(\mathrm{O}=3, \mathrm{E}=3.1, p=.618)$.

Attachment with child gender. No combinations involving attachment and gender were linked with particularly high or low likelihood of the problem trajectory.

Three-domain results. Finally, attachment security was evaluated in combinations containing two other domains (Table 7). Including an additional domain provides a more specific definition of the child's developmental context and provides a means of "zeroing in" on those individual children most likely to be at the extremes in terms of problem behavior. Three-domain combinations represented the final step in the analyses because the small number of cases exhibiting the high problem trajectory precluded testing four-domain combinations. For the three-domain analyses, family ecology was dichotomized to distinguish the multiproblem category from the delinquent and low-risk categories.

Attachment with parenting and family ecology. Over one-third $(35.7 \%)$ of the insecurely attached children exposed to highrisk parenting and living in multiproblem family environments were classified with the problem behavior trajectory, clearly representing a significant type $(\mathrm{O}=5, \mathrm{E}=1.8, p=$ .022). However, securely attached children exposed to the same conditions displayed the high problem pathway no more often than expected by chance $(\mathrm{O}=1, \mathrm{E}=1.2, p=.666)$. Of the children who experienced positive par- 
Table 7. Three domain patterns associated with problem trajectory

\begin{tabular}{|c|c|c|c|c|c|}
\hline & \multicolumn{2}{|c|}{$\begin{array}{l}\text { Trajectory } \\
\left(F_{\mathrm{O}} / F_{\mathrm{E}}\right)\end{array}$} & \multirow{2}{*}{$\begin{array}{c}\text { Exact } \\
\text { Probability }\end{array}$} & \multirow{2}{*}{$\begin{array}{c}\text { Problem } \\
\text { Trajectory } \\
(\%)\end{array}$} & \multirow[b]{2}{*}{ Result } \\
\hline & Problem & Typical & & & \\
\hline \multicolumn{6}{|l|}{ Parenting/ecology/attachment } \\
\hline Pos. par./low ecol./secure & $1 / 4.5$ & $33 / 29.5$ & .036 & 2.9 & Antitype \\
\hline Pos. par./low ecol./insecure & $6 / 5.4$ & $35 / 35.6$ & .459 & 14.6 & \\
\hline Pos. par./risk ecol./secure & $0 / 0.4$ & $3 / 2.6$ & 655 & 0 & \\
\hline Pos. par./risk ecol./insecure & $0 / 0.7$ & $5 / 4.3$ & .491 & 0 & \\
\hline Risk par./low ecol./secure & $4 / 3.3$ & $21 / 21.7$ & .420 & 16.0 & \\
\hline Risk par./low ecol./insecure & $5 / 4.8$ & $32 / 32.2$ & .560 & 13.5 & \\
\hline Risk par./risk ecol./secure & $1 / 1.2$ & $8 / 7.8$ & .666 & 11.1 & \\
\hline Risk par./risk ecol./insecure & $5 / 1.8$ & $9 / 12.2$ & .022 & 35.7 & Type \\
\hline \multicolumn{6}{|l|}{ Parenting/negativity/attachment } \\
\hline Pos. par./low neg./secure & $1 / 3.3$ & $24 / 21.7$ & .122 & 4.0 & \\
\hline Pos. par./low neg./insecure & $4 / 5.0$ & $34 / 33.0$ & .412 & 10.5 & \\
\hline Pos. par./high neg./secure & $0 / 1.6$ & $12 / 10.4$ & .174 & 0 & \\
\hline Pos. par./high neg./insecure & $2 / 1.0$ & $6 / 7.0$ & .282 & 25 & \\
\hline Risk par./low neg./secure & $2 / 2.9$ & 20/19.1 & .423 & 9.1 & \\
\hline Risk par./low neg./insecure & $3 / 3.8$ & $26 / 25.2$ & .448 & 10.3 & \\
\hline Risk par./high neg./secure & $3 / 1.6$ & 9/10.4 & .195 & 25.0 & \\
\hline Risk par./high neg./insecure & $7 / 2.9$ & $15 / 19.1$ & .012 & 31.8 & Type \\
\hline \multicolumn{6}{|l|}{ Ecology/negativity/attachment } \\
\hline Low ecol./low neg./secure & $3 / 5.3$ & $38 / 35.7$ & .164 & 7.3 & \\
\hline Low ecol./low neg./insecure & $5 / 7.4$ & $52 / 49.6$ & .178 & 8.8 & \\
\hline Low ecol./high neg./secure & $2 / 2.3$ & $16 / 15.7$ & .575 & 11.1 & \\
\hline Low ecol./high neg./insecure & $6 / 2.9$ & $16 / 19.1$ & .045 & 27.3 & Type \\
\hline Multirisk ecol./low neg./secure & $0 / 0.8$ & $6 / 5.2$ & .427 & 0 & \\
\hline Multirisk ecol./low neg./insecure & $2 / 1.4$ & 9/9.6 & .433 & 18.2 & \\
\hline Multirisk ecol./high neg./secure & $1 / 0.8$ & $5 / 5.2$ & .573 & 16.7 & \\
\hline Multirisk ecol./high neg./insecure & $3 / 1.0$ & $5 / 7.0$ & .069 & 37.5 & \\
\hline \multicolumn{6}{|l|}{ Negativity/gender/attachment } \\
\hline Low neg./female/secure & $2 / 2.3$ & $16 / 15.7$ & .575 & 11.1 & \\
\hline Low neg./female/insecure & $4 / 4.2$ & $28 / 27.8$ & .594 & 12.5 & \\
\hline Low neg./male/secure & $1 / 3.8$ & $28 / 25.2$ & .074 & 3.4 & \\
\hline Low neg./male/insecure & $3 / 4.7$ & $33 / 31.3$ & .262 & 8.3 & \\
\hline High neg./female/secure & $0 / 1.3$ & $10 / 8.7$ & .238 & 0 & \\
\hline High neg./female/insecure & $2 / 1.4$ & 9/9.6 & .433 & 18.2 & \\
\hline High neg./male/secure & $3 / 1.8$ & $11 / 12.2$ & .268 & 21.4 & \\
\hline High neg./male/insecure & $7 / 2.5$ & $12 / 16.5$ & .004 & 36.8 & Type \\
\hline
\end{tabular}

enting in low-risk family environments, only $2.9 \%$ with secure attachments developed the problem trajectory, representing an antitype $(\mathrm{O}=1, \mathrm{E}=4.5, p=.036)$. On the other hand, the expected percentage of their counterparts with insecure attachments developed the problem trajectory. It should be noted that the pattern of results observed in this more differentiated analysis of context suggests the findings reported in the previous two-domain analyses were due to children experiencing risk in both the parenting and family ecology domains.

Attachment with parenting and infant negativity. Insecurely attached children who were rated high on infant negativity and who experienced high-risk parenting were significantly more likely to show the problem trajectory $(\mathrm{O}=7, \mathrm{E}=2.9, p=.012)$. Although the probability of the problem trajectory was elevated for securely attached children under sim- 
ilar circumstances, it was not statistically significant $(\mathrm{O}=3, \mathrm{E}=1.6, p=.195)$. Positive parenting coupled with secure attachment translated to a low likelihood of the problem trajectory regardless of ratings on infant negativity.

Attachment with family ecology and infant negativity. Securely and insecurely attached children with low-risk family environments and low ratings on negativity had similar likelihood of showing the problem trajectory. However, differential rates for securely and insecurely attached children were pronounced for contexts with risk in the domains of family ecology, infant negativity, or both. Insecurely attached children with high ratings of negativity but low-risk family ecology were identified as a type $(\mathrm{O}=6, \mathrm{E}=2.9, p=.045)$. Insecurely attached children encountering risk in both domains had the highest likelihood of developing the problem trajectory but did not receive designation as a type due to low frequencies $(\mathrm{O}=3, \mathrm{E}=1.0, p=.069)$.

Three-domain combinations with gender. Only one statistically significant type emerged when attachment and gender were analyzed in three-way combination with parenting, family ecology, and infant negativity. The proportion of insecurely attached boys with reports of high infant negativity who also displayed the problem trajectory $(36.8 \%)$ was significantly higher than expected by chance $(\mathrm{O}=7, \mathrm{E}=$ $2.5, p=.004)$.

\section{Types of insecure attachment}

Follow-up analyses were conducted to determine whether particular types of insecure attachment were associated with development of the problem trajectory. Correspondences with the problem trajectory were examined for the attachment categories alone and then in combination with each other domain. Results are reported in Table 8.

Attachment alone. Children classified with the avoidant pattern of attachment at 12 months had the highest probability of a problem trajectory $(23.5 \%)$, and this rate identified chil- dren with avoidant attachment as a statistically significant type $(\mathrm{O}=8, \mathrm{E}=4.4, p=.045)$.

Attachment with other domains. Based on the cross-domain analyses, three combinations involving avoidant attachment were designated statistically significant types. Of the avoidantly attached children in the combined pool of lowrisk and delinquent family environments, $25.6 \%$ exhibited the problem trajectory $(\mathrm{O}=$ $7, \mathrm{E}=3.5, p=.038)$. Of the children classified for avoidant attachment and high infant negativity, $40 \%$ were also classified into the problem trajectory group $(\mathrm{O}=4, \mathrm{E}=1.3, p=$ .027). Finally, among avoidantly attached boys, $35.3 \%$ displayed the problem trajectory $(\mathrm{O}=6$, $\mathrm{E}=2.2, p=.012$ ).

\section{Discussion}

This study is among the first to examine disruptive problem behaviors during the preschool period using person-oriented statistical methods capable of distinguishing distinct trajectory classes. Latent variable GMM identified two very different problem behavior trajectories for children from 2 to 4.5 years in age. A majority of children in this sample demonstrated the decline in problem behaviors typical of the preschool period (Campbell, 1995; Spieker et al., 1999). In contrast, a small proportion of children with high initial levels of disruptive behaviors exhibited a pattern of escalating problem behaviors over time. Although the two class model provided the best fit to the data, the large, nonproblematic category may obscure heterogeneous trajectories reflecting different developmental pathways. For example, using longitudinal data across 2-8 years of age from a larger sample, Shaw and colleagues (2003) employed a semiparametric mixture model and identified four problem behavior trajectories (high persistent, high desister, moderate desister, and low persistent). Consistent with the typical trajectory class of the present study, the last three categories described by Shaw et al. (2003) had comparable (i.e., approximately parallel) downward slopes and varied primarily on initial intercepts. Resembling the problem trajectory in the present study, the high persistent group, 
Table 8. Attachment patterns and associations with problem trajectory

\begin{tabular}{|c|c|c|c|c|c|}
\hline & \multicolumn{2}{|c|}{$\begin{array}{l}\text { Trajectory } \\
\left(F_{\mathrm{O}} / F_{\mathrm{E}}\right)\end{array}$} & \multirow{2}{*}{$\begin{array}{c}\text { Exact } \\
\text { Probability }\end{array}$} & \multirow{2}{*}{$\begin{array}{l}\text { Problem } \\
\text { Trajectory } \\
(\%)\end{array}$} & \multirow[b]{2}{*}{ Result } \\
\hline & Problem & Typical & & & \\
\hline \multicolumn{6}{|l|}{ Attachment alone } \\
\hline Secure & $6 / 9.2$ & $65 / 61.8$ & .101 & 8.5 & \multirow{4}{*}{ Type } \\
\hline Avoidant & $8 / 4.4$ & $26 / 29.6$ & .045 & 23.5 & \\
\hline Resistant & $2 / 2.9$ & $20 / 19.1$ & .427 & 9.1 & \\
\hline Disorganized & $6 / 5.5$ & $36 / 36.5$ & .480 & 14.3 & \\
\hline \multicolumn{6}{|l|}{ Parenting and attachment } \\
\hline Pos. par./secure & $1 / 4.8$ & $36 / 32.2$ & .023 & 2.7 & \multirow[t]{8}{*}{ Antitype } \\
\hline Pos. par./avoid. & $4 / 2.5$ & $15 / 16.5$ & .223 & 21.1 & \\
\hline Pos. par./resist. & $0 / 0.9$ & 7/6.1 & .367 & 0 & \\
\hline Pos. par./disorg. & $2 / 2.6$ & $18 / 17.4$ & .495 & 10.0 & \\
\hline High-risk par./secure & $5 / 4.5$ & $29 / 29.5$ & .472 & 14.7 & \\
\hline High-risk par./avoid. & $4 / 2.0$ & $11 / 13.0$ & .113 & 26.7 & \\
\hline High-risk par./resist. & $2 / 1.8$ & $12 / 12.2$ & .574 & 14.3 & \\
\hline High-risk par./disorg. & $4 / 2.9$ & $18 / 19.1$ & .319 & 18.2 & \\
\hline \multicolumn{6}{|c|}{ Family ecology and attachment } \\
\hline Low-risk ecol./secure & $5 / 7.7$ & $54 / 51.3$ & .147 & 8.5 & \multirow{8}{*}{ Type } \\
\hline Low-risk ecol./avoid. & $7 / 3.5$ & $20 / 23.5$ & .038 & 25.9 & \\
\hline Low-risk ecol./resist. & $1 / 2.6$ & $19 / 17.4$ & .227 & 5.0 & \\
\hline Low-risk ecol./disorg. & $3 / 4.2$ & $29 / 27.8$ & .365 & 9.4 & \\
\hline Multiprob. ecol./secure & $1 / 1.6$ & $11 / 10.4$ & .519 & 8.3 & \\
\hline Multiprob. ecol./avoid. & $1 / 0.9$ & 6/6.1 & .630 & 14.3 & \\
\hline Multiprob. ecol./resist. & $1 / 0.3$ & $1 / 1.7$ & .244 & 50.0 & \\
\hline Multiprob. ecol./disorg. & $3 / 1.3$ & $7 / 8.7$ & .125 & 30.0 & \\
\hline \multicolumn{6}{|c|}{ Infant negativity and attachment } \\
\hline Low neg./secure & $3 / 6.1$ & $44 / 40.9$ & .086 & 6.4 & \multirow{8}{*}{ Type } \\
\hline Low neg./avoid. & $4 / 3.1$ & $20 / 20.9$ & .382 & 16.7 & \\
\hline Low neg./resist. & $0 / 2.1$ & $16 / 13.9$ & .096 & 0 & \\
\hline Low neg./disorg. & $3 / 3.6$ & $25 / 24.4$ & .486 & 10.7 & \\
\hline High neg./secure & $3 / 3.1$ & $21 / 20.9$ & .618 & 12.5 & \\
\hline High neg./avoid. & $4 / 1.3$ & $6 / 8.7$ & .027 & 40.0 & \\
\hline High neg./resist. & $2 / 0.8$ & $4 / 5.2$ & .176 & 33.3 & \\
\hline High neg./disorg. & $3 / 1.8$ & $11 / 12.2$ & .268 & 21.4 & \\
\hline \multicolumn{6}{|l|}{ Child gender and attachment } \\
\hline Female/secure & $2 / 3.6$ & $26 / 24.4$ & .250 & 7.1 & \multirow{8}{*}{ Type } \\
\hline Female/avoid. & $2 / 2.2$ & $15 / 14.8$ & .614 & 11.8 & \\
\hline Female/resist. & $0 / 0.9$ & 7/6.1 & .370 & 0 & \\
\hline Female/disorg. & $4 / 2.5$ & $15 / 16.5$ & .219 & 21.1 & \\
\hline Male/secure & $4 / 5.6$ & $39 / 37.4$ & .291 & 9.3 & \\
\hline Male/avoid. & $6 / 2.2$ & $11 / 14.8$ & .012 & 35.3 & \\
\hline Male/resist. & $2 / 2.0$ & $13 / 13.0$ & .611 & 13.3 & \\
\hline Male/disorg. & $2 / 3.0$ & $21 / 20.0$ & .394 & 8.7 & \\
\hline
\end{tabular}

Note: Results for securely attached children appear in previous tables.

representing $6 \%$ of the sample, had the highest intercept and a nonsignificant (i.e., flat) slope.

The identification of the distinct high problem trajectory in this study is consistent with previous research suggesting a particular developmental pathway characterized by an early onset of extreme and chronic conduct problems (Campbell et al., 2000; Hinshaw et al., 1993; Moffitt, 1993; Patterson et al., 1991). The statistically significant positive slope for the problem trajectory class during this early preschool period is particularly interesting given developmental models proposing that 
reinforcing cycles of negative interaction between child and environment explain how patterns of externalizing behavior are established and maintained (Loeber \& Hay, 1997; Moffitt, 1993; Patterson et al., 1989).

To investigate the myriad factors contributing to the development of the qualitatively different problem behavior pathway, the multiple-domain model proposed by Greenberg and colleagues (Greenberg, 1999; Greenberg et al., 1993) served as the framework for a person-oriented analysis examining whether certain configurations of overlapping risks were linked with escalating problem behaviors. As a preliminary step, children were classified according to characteristic profiles on each of the four domains in the model. In particular, a wealth of data across numerous relevant variables and across multiple time points was used to establish risk profiles for the broad domains of parental management and socialization and family ecology.

Previous research suggests stronger associations are found when studies measure combinations of parent behaviors (patterns), as opposed to single behaviors (Rothbaum \& Weisz, 1994). A long history of person-oriented research has identified distinctive typologies of parenting styles as contexts for child development (Baumrind, 1971; Darling \& Steinberg, 1993; Maccoby \& Martin, 1983). Although the "positive," "harsh," and "disengaged" parenting groups derived through cluster analysis shared certain conceptual similarities with previous designations of parenting styles (e.g., authoritative, authoritarian, neglectful), only the distinction between positive parenting and the combined high-risk groups was supported by significant differences on validation measures.

Although relatively less attention has been given to identifying typologies of family ecology, it makes sense to do so because many such risks are known to co-occur, and a particular group of children experiencing high risk on multiple factors may be responsible for the correlation with behavior problems observed across numerous individual factors (Radke-Yarrow et al., 1995; Rutter et al., 1975). The three family ecology groups derived by cluster analysis confirmed the co- occurrence of the four indicator variables, with the groups being distinguished primarily by the level (low, medium, high) of the factors rather than the pattern (except delinquency). Nevertheless, the distinctions between the lowrisk, delinquent, and multiproblem groups were validated on other family ecology variables. It is important to note the relativistic nature of risk status in these domains, based as it is upon a sample of adolescent mothers who are likely, on average, to be more disadvantaged than the general population.

With respect to the domain of parentinfant attachment, fewer than half of the children in this sample were securely attached (B, $42 \%$ ), while the insecure classifications were overrepresented (A, 21\%; C, 12\%; D, 25\%). In their recent meta-analysis, van IJzendoorn, Schuengel, and Bakermans-Kranenburg (1999) reported an A-B-C-D distribution of 15, 62, 9 , and $15 \%$, respectively, based on over 2,000 cases from 15 normative US samples. However, the distribution for four samples of adolescent mothers representing a total of 282 mother-infant dyads was significantly different, with A-B-C-D proportions of 33, 40, 4, and $23 \%$, respectively. Thus, the classification of attachment for adolescent mothers and their children in the present study resembles results for similar samples of adolescent mothers and provides further evidence of substantial variation from the normative distribution.

When each individual domain in the Greenberg model was tested for its association with the problem behavior trajectory, only infant negativity was found to have a statistically significant correspondence. Children rated high on negativity as infants were three times more likely to exhibit the problem trajectory in the preschool period. Although the odds of developing the problem trajectory were about twice as great for children classified into the highrisk compared to the low-risk categories for attachment, or parenting, or family ecology, these bivariate effects were not quite large enough for the possibility of independence to be ruled out. The probability of the problem trajectory was not differentiated by child gender either.

The results of the single-domain analyses are consistent with the contention that risk in 
a single domain is not necessarily sufficient to lead to disorder (Greenberg, 1999). Regarding parent-child attachment, Greenberg has emphasized that a search for main effects on behavior problems is inappropriate given the theory, which stresses the role of attachment in interaction with other factors (personal communication, June 25, 1999). Accordingly, the present study focused on the proposition that early attachment would contribute to later behavior depending upon the nature of the child's subsequent experience within certain environmental contexts (Bowlby, 1973; Sroufe et al., 1999). The question was whether attachment in conjunction with other factors would identify children with a higher probability of problem behaviors.

As expected, in the two-domain analyses attachment security was found to interact with other domains to define unique combinations of early risk representing types and antitypes. Insecurely attached children with high levels of infant negativity had a significantly greater likelihood of displaying the high problem behavior trajectory, whereas securely attached children with the same risk status did not. Kerr, Tremblay, Pagani, and Vitaro (1997) interpret this pattern of results as evidence of a protective effect. A stronger test of a protective effect is a direct comparison between securely and insecurely attached children within the same context. For any given context, a higher proportion of insecurely attached children developed the problem trajectory than did their securely attached counterparts. Focusing on the 31 children in multiproblem family environments, for instance, those with insecure attachment in infancy were almost four times more likely to later develop the problem trajectory than those with secure attachment (odds ratio $=3.9$ ). Similarly, among children rated high on negativity as infants, insecure attachment tripled the likelihood of a problem trajectory (odds ratio $=3.0$ ). Despite the differences between securely and insecurely attached children in these high-risk situations, the two direct comparisons are not statistically significant. Statistical power to detect effects of this magnitude was .27 and .36, respectively.

Nevertheless, the identification of a type defined by insecurity in combination with in- fant negativity is highly congruent with previous research observing the highest levels of externalizing behaviors among children with difficult temperamental characteristics and insecure attachment (Burgess et al., 2003; Shaw et al., 1996). Likewise, the pattern for insecurity in combination with parenting and with family ecology is very consistent with previous studies reporting interactions between environmental factors and insecure attachment (Erickson et al., 1985; Lewis et al., 1984; Lyons-Ruth et al., 1993). Taken together, these results suggest that attachment security is a distinguishing factor in the context of other risks.

The role of attachment security was also apparent at the other end of the risk spectrum. In circumstances characterized by positive parenting, securely attached children were significantly less likely to develop the problematic trajectory, but their insecurely attached counterparts were not (odds ratio $=5.4$ ). These findings suggest that secure attachment has a protective advantage even in lower risk situations, which is consistent with research showing greater levels of prosocial, cooperative behavior, and social competence associated with attachment security (Arend, Gove, \& Sroufe, 1979; Booth, Rose-Krasnor, \& Rubin, 1991).

The three-domain analyses provided additional specificity regarding children at risk for the problem behavior trajectory. For example, there was a high probability of developing the problem behavior trajectory when insecure attachment and high-risk parenting also combined with multiproblem family ecology or high infant negativity. Conversely, those with a very low likelihood of developing the problem trajectory were securely attached children exposed to low risk in both the parenting and family ecology domains. The individual children identified as more likely or less likely to have problem behaviors in this round of analyses are, of course, a subset of the ones identified in the two-domain analyses. However, the addition of a domain further distinguishes which children are likely to demonstrate the atypical pattern of behavior. For example, not all insecure children with less adequate parenting are at substantially greater risk to de- 
velop clinical problems, just those who also experience a multiproblem family environment or who display high levels of negativity in the first year of life. The more detailed analyses also reveal that certain combinations involving risk in only two domains can be identified as types with high likelihood of the problem trajectory. Insecurity combined with high infant negativity appears to be a potent combination even in the context of low-risk family ecology. Analyses including child gender indicated that boys are particularly susceptible to this combination of attachment insecurity with infant negativity.

Overall, the results of the main analyses support the premise that overlapping domains of risk define particular subgroups of children more likely than others to develop problem behaviors (Greenberg, 1999; Greenberg et al., 1993). As expected, when early attachment security is considered in the context of multiple risk domains, it plays a role in distinguishing the probability of a problematic behavior trajectory (Bowlby, 1973; Sroufe et al., 1999). All types identified with higher likelihood of the problem trajectory involve attachment insecurity in combination with high risk in at least one other domain, while all antitypes with low likelihood of the problem trajectory involve secure attachment in low-risk circumstances. Finally, the differentiation of context with consideration of multiple domains gives further support to the notion that the accumulation of risk factors in early childhood is particularly detrimental (Sanson et al., 1991; Shaw et al., 1994).

Links between attachment and development of the problem trajectory were further clarified by investigating the three different classifications of insecure attachment. The follow-up analyses revealed that children with avoidant attachment patterns had significantly higher risk for the problem trajectory than children with any other attachment classification. In a direct comparison against secure attachment status, this main effect of avoidance more than tripled the odds of the problem trajectory (odds ratio $=3.3, p=.04$ ). In contrast, the prevalence of the problem trajectory for children with disorganized attachment was very close to that of the sample as a whole. Finding externalizing behaviors to be associated with avoidance is consistent with results in numerous earlier studies, although some were conducted prior to classification of disorganized status or had too few cases to analyze other insecure categories (Burgess et al., 2003; Erickson et al., 1985). The results do not provide evidence that disorganized attachment alone increases the likelihood of escalating problem trajectories, as would have been predicted (Lyons-Ruth, 1996).

The timing of problem behavior assessments may explain the findings of this study in relation to previous research and also highlight two different pathways to externalizing problems. In contrast to the current examination of early-starter problem behaviors from 2 to 4.5 years of age, studies indicating higher risk for children with the disorganized pattern have relied on reports of externalizing behavior assessed at 4.5 years or older (Carlson, 1998; Lyons-Ruth et al., 1993; Munson et al., 2001; Shaw et al., 1996). Changes during this developmental period in cognitive, language, and behavioral domains have implications for the organization of internal representational models, the use of defensive strategies, and the functioning of the goal-corrected partnership (Cicchetti, Cummings, Greenberg, \& Marvin, 1990; Crittenden, 1992). It may be that consequences of disorganized attachment become apparent later in the preschool period when children develop the controlling-punitive and coercive-aggressive modes of interaction observed in preschool classification systems (see Solomon \& George, 1999; Teti, 1999). On the other hand, avoidant attachment may be associated with patterns of disruptive behavior that have earlier manifestations and different origins, as discussed below. In support of this interpretation, the other study finding avoidant attachment but not disorganized attachment predictive of externalizing behaviors measured the outcome at 3 years of age (Belsky \& Fearon, 2002).

Somewhat contrary to expectations, avoidantly attached children were more likely than anticipated to develop the problem trajectory in lower risk and delinquent family environments. In addition, the proportion of avoidant children with the problem trajectory 
was elevated in both the positive and highrisk parenting contexts. This pattern of results, which suggests that avoidant attachment may increase the risk of problem behaviors regardless of environmental stress, seems at odds with the finding of Belsky and Fearon (2002) that children with avoidant attachment were most vulnerable to modest levels of adversity. However, this discrepancy might be explained by the relative levels of risk between the large, national sample of the NICHD study (Belsky \& Fearon, 2002) and the highrisk sample of adolescent mothers in the current study. Belsky and Fearon found the effect of avoidant attachment most pronounced in the presence of two risk factors on an index compiled across parenting and family ecology domains. It is highly likely that most parents in the current sample, even those designated lower risk, would have been classified with two or more risks on the Belsky and Fearon criteria. In support of this interpretation, comparison of two measures used in both studies to assess maternal depression and the home environment (CES-D, HOME) revealed that the means for the low-risk family ecology group in the present study were significantly higher than the NICHD sample average on both variables. Taken together, the findings of these two studies raise the question of whether children with avoidant attachment have lower thresholds of stress tolerance than other children. It is interesting to note that children in the present study with either resistant or disorganized classifications were the ones more responsive to risk conditions, with greater probability of the problem trajectory under highrisk circumstances.

Avoidant attachment in combination with high levels of infant negativity was identified as a type at risk for increasing conduct problems. Burgess and colleagues (2003), who found that an uninhibited, fearless temperament interacted with avoidant attachment to predict higher levels of problem behaviors, suggested that fearlessness and behavioral undercontrol combined with the underlying anger and aggression of avoidant children could be a powerful recipe for conduct problems. Because the temperamental dimension under consideration in the present study was nega- tive emotionality, reflecting strong negative reactivity and proneness to distress, a slightly different developmental transaction may be operable.

When children who are easily aroused and distressed also anticipate hostility and rejection in social interactions, their response may be aggressive or destructive. For example, emotionally labile children may demonstrate a particularly high degree of the hypervigilance to cues of rejection, hostility, or threat characteristic of reactive aggression (Dodge, 1993; Downey et al., 1998). If this is the case, a temperament by environment interaction (e.g., negative affectivity heightening the response to events) may account for the lower threshold to environmental stress discussed above (Rothbart \& Bates, 1998). In addition, a disposition to negative emotionality may exacerbate two important features of reactive aggression: intense autonomic arousal, and lack of emotional and behavioral self-control in response to perceived threats (Dodge, Lochman, Harnish, Bates, \& Pettit, 1997).

Another possible mechanism is suggested by the work of Belsky, Hsieh, and Crnic (1998), who proposed that children with varying levels of infant negativity may be differentially susceptible to child-rearing practices and parent-child interactions. They found that the quality of parenting was more predictive of externalizing behavior for children with higher levels of infant negativity. With reference to the present study, children with greater negative emotionality may be more vulnerable to disruptive acting out when they lack a safe haven and secure base offered by an attachment figure. In contrast, less emotionally reactive children may be better equipped to regulate their own behavior even when they cannot rely on an attachment figure for security.

Avoidant boys also were identified as a type with greater probability for externalizing problems. Assuming children with avoidant attachment have working models predisposing them to attribute hostile intent to others, slower development of communication skills and social competence in boys during this developmental period may make them less capable than girls to resolve perceived slights in a nondisruptive manner (Keenan \& Shaw, 1997). In 
addition, gender socialization of males may permit them to counter perceived threats and express anger and frustration in more overt, confrontational ways.

Although the discussion has centered on cells identified as statistically significant types and antitypes, the person-oriented analyses presented in this study are informative in several other ways. First, an examination of row totals indicates that some risk conditions rarely occur. For example, very few cases of positive parenting coincided with distressed family ecology. Second, the analyses suggest that subsets of children with very high or very low scores across multiple domains may be responsible for associations between problem behaviors and individual risk factors. Third, although the accumulation of risk factors was generally more predictive, the findings indicate that different individual risk factors and combinations of risk factors are differentially associated with the problem outcome. Consequently, it is informative to look at specific combinations rather than a cumulative index of risk factors. Fourth, inspection of the contingency tables provides a reminder that not all children fitting a particular categorical description will have the same outcome (multifinality) and that children with the problem behavior trajectory reflect a variety of early risk conditions (equifinality). The fact that children with the very worst confluence of risks (e.g., high-risk parenting, multiproblem ecology, insecure attachment) had roughly a one in three chance of demonstrating the problem trajectory highlights the probabilistic rather than deterministic nature of development (Sroufe, 1997).

\section{Limitations}

The results presented here must be interpreted with some caution due to certain limitations of the study. The analysis was based on the assessment of mother-child attachment security at 12 months, but attachment organization is subject to change as the relationship evolves and circumstances vary. Change in attachment status is associated with stressful life events, parenting attributes, and changes in caregiving arrangements (Egeland \& Farber, 1984; Thompson, Lamb, \& Estes, 1983;
Vaughn, Egeland, Sroufe, \& Waters, 1979). Thus, more dynamic modeling techniques would better reflect actual developmental processes. In addition, as in other research focusing exclusively on mother-child attachment, the more general role of attachment processes could have been obscured because children can have several attachment figures (Pianta, 1992). This shortcoming is perhaps more relevant in the case of adolescent mothers, who may not always be primary attachment figures given their use of extended family for support and assistance in child rearing (Field, Widmayer, Adler, \& De Cubas, 1990; Garcia Coll, Hoffman, \& Oh, 1987; Keller, Gilchrist, \& Spieker, 2000).

Despite the use of missing data procedures in the GMM of behavior trajectories, some cases were lost to missing data, raising the possibility of bias due to differential attrition. Comparisons between cases included in the analyses and those excluded revealed few notable differences on demographic, family background, or attachment and child behavior ratings. Nevertheless, the possibility remains that more troubled parents and children may have been underrepresented in the analysis.

The study relied heavily on a single informant as the source of data. With the exception of attachment and maternal warmth, the data used in constructing the categorical variables were obtained through maternal report. Thus, there exists the possibility of bias associated with both common informant and common method variance. For example, the mother's emotional state may have biased her perceptions of the family situation, her parenting strengths and weaknesses, and her child's behavior. Despite the potential for distortions introduced by depression, dysphoria or other influences on parental perceptions, the use of caregivers as reporters has certain advantages, such as greater familiarity with the child across contexts and awareness of low base rate behaviors (Youngstrom, Izard, \& Ackerman, 1999). In the present study, the potential for distortion due to depression does not necessarily threaten the validity of the findings regarding attachment security based on the within-group contrasts. Differences between secure and insecure attachment were evalu- 
ated within family ecology clusters, effectively controlling for depressive symptoms through subsample selection.

Another issue of measurement involves the assessment of infant negativity. As in much research examining associations between temperamental characteristics and behavioral symptoms, infant negativity was based on maternal perceptions reported on a rating scale. Concerns about the possibility of findings biased by overlapping constructs or common method variance are raised when studies assessing infant negativity with parent ratings report associations (e.g., Bates et al., 1985) but those using more observationally based assessments do not (e.g., Belsky et al., 1998). These issues are compounded by research indicating relatively weak correspondences between parent and observer ratings of temperament (Seifer, Sameroff, Barrett, \& Krafchuk, 1994). Nevertheless, Rothbart and Bates (1998) point out that each assessment approach has strengths and weaknesses, and parent-report measures continue to be a preferred method of measuring temperament. Although there is a danger of spurious associations between temperament and behavioral outcomes due to overlapping items or a common rater, the use of theoretical and empirical methods to eliminate this "contamination" effect still yields meaningful associations (Lengua, West, \& Sandler, 1998). In the present study, these concerns were somewhat mitigated by the temporal spacing between the assessment of negativity in the child's first year of life and the rating of disruptive behaviors starting in the third year of life. Also, distinctions involving children with secure and insecure attachment were examined within infant negativity groups.

The number of single cells examined in the sequential analysis was large, which might suggest inflation of Type I error. However, as noted earlier, it is unclear that "nested" multistage analyses are subject to studywise error in the same way as multiple independent and simultaneous tests. The risk of spurious findings with increasing numbers of tests as the contingency tables expanded was offset to some degree by a corresponding reduction in statistical power as cell sizes became smaller (Agresti, 1990). Another consideration is the greater risk of Type II error in ecological research (Bronfenbrenner \& Morris, 1998). Also, findings were consistent with theoretical expectations, suggesting they were not simply random associations.

A final study limitation concerns the issue of categorization of individuals. The exact test of cell frequencies based on the fixed-margins model assumes correct categorization of each case, and results are susceptible to misclassification on either dimension of the table. In this study, the precision of classification into problem behavior trajectory groups could be controlled by selecting a criteria for posterior probabilities $(p>.75)$, but the cluster analytic procedures used for other domains forced every case into the best category. Furthermore, the classifications derived in this study were highly sample dependent due to the empirical procedures drawing directly from the data. In addition, the clustering results are strongly influenced by the variables to represent each domain. Replication of the categorical groupings in the outcome and the risk domains in other samples is required before attempting to make inferences to the general population. Given the special characteristics of the teen parent sample, the results should not be generalized to individuals or populations different from those involved in the study.

\section{Conclusions}

This study was based on the premise that early attachment interacts with child characteristics and subsequent experience to influence later problem behaviors. The study sought to identify particular constellations of cross-domain risk involving attachment that were associated with a high problem behavior trajectory. Several broad conclusions can be drawn from the results (a) avoidant attachment was associated with the probability of the problem trajectory; (b) attachment status played a role in defining particular developmental pathways associated with higher or lower probabilities of problem behavior; (c) given a particular pattern of risk exposure, attachment security served a protective function; and (d) the likelihood of a problem trajectory increased with the accumulation of risk factors, but the par- 
ticular configuration of risk sometimes did make a difference. These conclusions are consistent with attachment theory and the propositions of the model which served as the basis for the study (Greenberg, 1999; Greenberg et al., 1993; Sroufe et al., 1999).

Evidence that the most effective interventions for the prevention of conduct problems are implemented before children reach school age underscores the importance of understanding the early origins of problem behaviors (Reid, 1993; Tremblay, LeMarquand, \& Vitaro, 1999). Knowledge of processes, sequential courses, and interactions among risk domains is essential for designing targeted interventions that modify relevant factors during appropriate developmental stages (Cicchetti, Toth, Bush, \& Gillespie, 1988; Coie, Watt, West, Hawkins, Asarrow, Markman, Ramey, Shure, \& Long, 1993). For example, a recent meta-analysis revealed that the most successful interventions for improving rates of secure attachment in high-risk groups employ relatively brief, behaviorally focused approaches beginning after 6 months of age (BakermansKranenburg, van IJzendoorn, \& Juffer, 2003).
Future research may find that preventing problem behaviors by early promotion of secure attachment is extremely cost effective.

The present study illustrates how systematic person-oriented analyses based on a model representing intersections among multiple ecological domains can identify particular constellations of early risk associated with distinct trajectories of preschool problem behaviors. Because types and antitypes imply a nonrandom link between preceding conditions and later outcomes, they can provide a focus for generating more specific hypotheses about intraindividual development as well as providing guidance in the clinical assessment of individual cases showing the same profile. For example, the present findings suggest a close examination of developmental pathways for boys with insecure-avoidant attachment and high levels of negative emotionality. Future research with larger samples may be able to identify other risk typologies with even greater specificity, and a focus on these subgroups may provide insights into particular developmental processes with implications for behavior and adjustment.

\section{References}

Abidin, R. R. (1990). Parent Stress Index-Short form. Charlottesville, VA: Pediatric Psychology Press.

Achenbach, T. M. (1991). Manual for the Child Behavior Checklist/4-18 and 1991 profile. Burlington, VT: University of Vermont Department of Psychiatry.

Achenbach, T. M. (1992). Manual for the Child Behavior Checklist/2-3 and 1992 Profile. Burlington, VT: University of Vermont Department of Psychiatry.

Achenbach, T. M., \& Edelbrock, C. (1981). Behavior problems and competencies reported by parents of normal and disturbed children aged four to sixteen. Monographs of the Society for Research in Child Development, 46(Serial No. 188).

Agresti, A. (1990). Categorical data analysis. New York: Wiley.

Aguilar, B., Sroufe, L. A., Egeland, B., \& Carlson, E. (2000). Distinguishing the early-onset/persistent and adolescent-onset antisocial behavior types: From birth to 16 years. Development and Psychopathology, 12, 109-132.

Ainsworth, M. D. S., Blehar, M. C., Waters, E., \& Wall, S. (1978). Patterns of attachment: A psychological study of the strange situation. Hillsdale, NJ: Erlbaum.

Aldenderfer, M. S., \& Blashfield, R. K. (1984). Cluster analysis. Newbury Park, CA: Sage.

Anderberg, M. R. (1973). Cluster analysis for applications. New York: Academic Press.

Arend, R., Gove, F. L., \& Sroufe, L. A. (1979). Continuity of individual adaptation from infancy to kindergar-

ten: A predictive study of ego-resiliency and curiosity in preschoolers. Child Development, 50, 950-959.

Azar, S. T., Robinson, D. R., Hekimian, E., \& Twentyman, C. T. (1984). Unrealistic expectations and problem-solving ability in maltreating and comparison mothers. Journal of Consulting and Clinical Psychology, 52, 687-691.

Azar, S. T., \& Rohrbeck, C. A. (1986). Child abuse and unrealistic expectations: Further validation of the Parent Opinion Questionnaire. Journal of Consulting and Clinical Psychology, 54, 867-868.

Azar, S. T., \& Twentyman, C. T. (1986). Cognitive behavioral perspectives on the assessment and treatment of child abuse. In P. C. Kendall (Ed.), Advances in cognitive behavioral research and therapy (Vol. 5, pp. 237). New York: Academic Press.

Bachman, J. G., O’Malley, P. M., \& Johnston, J. (1978). Youth in transition, Vol. 4: Adolescence to adulthoodChange and stability in the lives of young men. Ann Arbor, MI: Institute for Social Research.

Baker, P. C., \& Mott, F. L. (1989). NLSY child handbook 1989. Columbus, OH: Ohio State University, Center for Human Resource Research.

Bakermans-Kranenburg, M. J., van IJzendoorn, M. V., \& Juffer, F. (2003). Less is more: Meta-analyses of sensitivity and attachment interventions in early childhood. Psychological Bulletin, 129, 195-215.

Barnard, K. E. (1979). Instructor's learning resource manual. Seattle, WA: NCAST, University of Washington. 
Bates, J. E., Maslin, C. A., \& Frankel, K. A. (1985) Attachment security, mother-child interaction, and temperament as predictors of behavior-problem ratings at age three years. Monographs of the Society for Research in Child Development, 50(1-2, Serial No. 209), 167-193.

Baumrind, D. (1971). Current patterns of parental authority. Developmental Psychology Monographs, 4(1, Pt. 2).

Belsky, J., \& Fearon, R. M. P. (2002). Infant-mother attachment security, contextual risk, and early development: A moderational analysis. Development and Psychopathology, 14, 293-310.

Belsky, J., Hsieh, K., \& Crnic, K. (1998). Mothering, fathering, and infant negativity as antecedents of boys' externalizing problems and inhibition at age 3: Differential susceptibility to rearing influence? Development and Psychopathology, 10, 301-319.

Bergman, L. R., \& El-Khouri, B. (1987). Exacon: A Fortran 77 program for the exact analysis of single cells in a contingency table. Educational and Psychological Measurement, 47, 155.

Bergman, L. R., \& El-Khouri, B. M. (1998). SLEIPNER: A statistical package for pattern-oriented analyses, $V$ 2.0. Stockholm: Stockholm University Department of Psychology.

Bergman, L. R., \& Magnusson, D. (1997). A personoriented approach in research on developmental psychopathology. Development and Psychopathology, 9, 291-319.

Booth, C. L., Rose-Krasnor, L., \& Rubin, K. H. (1991). Relating preschoolers' social competence and their mothers' parenting behaviors to early attachment security and high-risk status. Journal of Social and Personal Relationships, 8, 363-382.

Bowlby, J. (1973). Attachment and loss: Vol. 2. Separation, anxiety and anger. New York: Basic Books.

Bretherton, I. (1985). Attachment theory: Retrospect and prospect. Monographs of the Society for Research in Child Development, 50(1-2, Serial No. 209).

Bronfenbrenner, U. (1977). Toward an experimental ecology of human development. American Psychologist, 32, 513-531.

Bronfenbrenner, U., \& Morris, P. A. (1998). The ecology of developmental processes. In R. M. Lerner (Ed.), Handbook of child psychology: Vol. 1. Theoretical models of human development (5th ed., pp. 9931023). New York: Wiley.

Brooks-Gunn, J., \& Furstenberg, F. F., Jr. (1986). The children of adolescent mothers: Physical, academic, and psychological outcomes. Developmental Review, 6, 224-251.

Burgess, K. B., Marshall, P. J., Rubin, K. H., \& Fox, N. A. (2003). Infant attachment and temperament as predictors of subsequent externalizing problems and cardiac physiology. Journal of Child Psychology and Psychiatry, 44, 819-831.

Caldwell, B. M., \& Bradley, R. H. (1984). Manual for the Home Observation for the Measurement of the Environment. Little Rock, AK: University of Arkansas Press.

Campbell, S. B. (1995). Behavior problems in preschool children: A review of recent research. Journal of Child Psychology and Psychiatry, 36, 113-149.

Campbell, S. B., Shaw, D. S., \& Gilliom, M. (2000). Early externalizing behavior problems: Toddlers and preschoolers at risk for later maladjustment. Development and Psychopathology, 12, 467-488.

Carlson, E. A. (1998). A prospective longitudinal study of attachment disorganization/disorientation. Child Development, 69, 1107-1128.

Carlson, E. A., \& Sroufe, L. A. (1995). Contribution of attachment theory to developmental psychopathology. In D. Cicchetti \& D. J. Cohen (Eds.), Developmental psychopathology: Vol. 1. Theory and methods (pp. 581-617). New York: Wiley.

Carter, A. S., Briggs-Gowan, M. J., Jones, S. M., \& Little, T. D. (2003). The Infant-Toddler Social and Emotional Assessment (ITSEA): Factor structure, reliability, and validity. Journal of Abnormal Child Psychology, $31,495-514$.

Cassidy, J. (1994). Emotion regulation: Influences of attachment relationships. Monographs of the Society for Research in Child Development, 59(2-3, Serial No. 240), 228-249.

Cassidy, J., \& Berlin, L. J. (1994). The insecure/ambivalent pattern of attachment: Theory and research. Child Development, 65, 971-981.

Cassidy, J., Kirsh, S. J., Scolton, K.-L., \& Parke, R.-D. (1996). Attachment and representations of peer relationships. Developmental Psychology, 32, 892-904.

Cicchetti, D., \& Cohen, D. J. (1995). Perspectives on developmental psychopathology. In D. Cicchetti \& D. J. Cohen (Eds.), Developmental psychopathology: Vol. 1. Theory and methods (pp. 3-20). New York: Wiley.

Cicchetti, D., Cummings, E. M., Greenberg, M. T., \& Marvin, R. S. (1990). An organizational perspective on attachment beyond infancy: Implications for theory, measurement, and research. In M. T. Greenberg, D. Cicchetti, \& E. M. Cummings (Eds.), Attachment in the preschool years: Theory, research, and intervention (pp. 3-49). Chicago: University of Chicago Press.

Cicchetti, D., \& Richters, J. (1993). Developmental considerations in the investigation of conduct disorder. Development and Psychopathology, 5, 331-344.

Cicchetti, D., \& Rogosch, F. (1996). Equifinality and multifinality in developmental psychopathology. Development and Psychopathology, 8, 597-600.

Cicchetti, D., Toth, S. L., Bush, M. A., \& Gillespie, J. F. (1988). Stage-salient issues: A transactional model of intervention. In E. D. Nannis \& P. A. Cowan (Eds.), Developmental psychopathology and its treatment. San Francisco, CA: Jossey-Bass.

Coddington, R. D. (1972). The significance of life events as etiologic factors in the diseases of children: II. A study of normal populations. Journal of Psychometric Research, 16, 205-213.

Coie, J. D., Watt, N. F., West, S. G., Hawkins, J. D., Asarnow, J. R., Markman, H. J., Ramey, S. L., Shure, M. B., \& Long, B. (1993). The science of prevention: A conceptual framework and some directions for a national research program. American Psychologist, 48, 1013-1022.

Coley, R. L., \& Chase-Lansdale, P. L. (1998). Adolescent pregnancy and parenthood: Recent evidence and future directions. American Psychologist, 53, 152-166.

Crick, N. R., \& Dodge, K. A. (1994). A review and reformulation of social information-processing mechanisms in children's social development. Psychological Bulletin, 115, 74-101.

Crittenden, P. M. (1992). Quality of attachment in the preschool years. Development and Psychopathology, 4, 209-241.

Darling, N., \& Steinberg, L. (1993). Parenting style as context: An integrative model. Psychological Bulletin, 113, 487-496. 
Deater-Deckard, K., Dodge, K. A., Bates, J. E., \& Pettit, G. S. (1998). Multiple risk factors in the development of externalizing behavior problems: Group and individual differences. Development and Psychopathology, 10, 469-493.

Dishion, T. J., French, D. C., \& Patterson, G. R. (1995). The development and ecology of antisocial behavior. In D. Cicchetti \& D. J. Cohen (Eds.), Developmental psychopathology: Vol. 2. Risk, disorder, and adaptation. New York: Wiley.

Dodge, K. A. (1993). Social-cognitive mechanisms in the development of conduct disorder and depression. Annual Review of Psychology, 44, 559-584.

Dodge, K. A., Lochman, J. E., Harnish, J. D., Bates, J. E., $\&$ Pettit, G. S. (1997). Reactive and proactive aggression in school children and psychiatrically impaired and chronically assaultive youth. Journal of Abnormal Psychology, 106, 37-51.

Downey, G., Lebolt, A., Rincon, C., \& Freitas, A. L. (1998). Rejection sensitivity and children's interpersonal difficulties. Child Development, 69, 1074-1091.

Duncan, T. E., Duncan, S. C., Strycker, L. A., Li, F., \& Alpert, A. (1999). An introduction to latent variable growth curve modeling: Concepts, issues, and applications. Mahwah, NJ: Erlbaum.

Eisenberg, N., \& Fabes, R. A. (1992). Emotion, regulation, and the development of social competence. In M. S. Clark (Ed.), Review of personality and social psychology: Vol. 14. Emotion and social behavior (pp. 119-150). Newbury Park, CA: Sage.

Erickson, M. F., Sroufe, L. A., \& Egeland, B. (1985). The relationship between quality of attachment and behavior problems in preschool in a high-risk sample. Monographs of the Society for Research in Child Development, 50, 147-166.

Fagot, B. I., \& Kavanagh, K. (1990). The prediction of antisocial behavior from avoidant attachment classifications. Child Development, 61, 864-873.

Field, T., Widmayer, S., Adler, S., \& De Cubas, M. (1990). Teenage parenting in different cultures, family constellations, and caregiving environments: Effects on infant development. Infant Mental Health Journal, $11,158-174$.

Garcia Coll, C. G., Hoffman, J., \& Oh, W. (1987). The social ecology and early parenting of Caucasian adolescent mothers. Child Development, 58, 955-963.

Goldberg, S. (1997). Attachment and childhood behavior problems in normal, at-risk, and clinical samples. In L. Atkinson \& K. J. Zucker (Eds.), Attachment and psychopathology (pp. 171-195). New York: Guilford Press.

Goldberg, S., Gotowiec, A., \& Simmons, R. J. (1995). Infant-mother attachment and behavior problems in healthy and chronically ill preschoolers. Development and Psychopathology, 7, 267-282.

Greenberg, M. T. (1999). Attachment and psychopathology in childhood. In J. Cassidy \& P. R. Shaver (Eds.), Handbook of attachment: Theory, research, and clinical applications (pp. 469-496). New York: Guilford Press.

Greenberg, M. T., DeKlyen, M., Speltz, M. L., \& Endriga, M. C. (1997). The role of attachment processes in externalizing psychopathology in young children. In L. Atkinson \& K. J. Zucker (Eds.), Attachment and psychopathology (pp. 196-222). New York: Guilford Press.

Greenberg, M. T., Speltz, M. L., \& DeKlyen, M. (1993). The role of attachment in the early development of disruptive behavior problems. Development and Psychopathology, 5, 191-213.

Greenberg, M. T., Speltz, M. L., DeKlyen, M., \& Jones, K. (2001). Correlates of clinic referral for early conduct problems: Variable- and person-oriented approaches. Development and Psychopathology, 13, 255-276.

Hinshaw, S. P., Lahey, B. B., \& Hart, E. L. (1993). Issues of taxonomy and comorbidity in the development of conduct disorder. Development and Psychopathology, $5,31-49$.

Huberty, C. J., DiStefano, C., \& Kamphaus, R. W. (1997). Behavioral clustering of school children. Multivariate Behavioral Research, 32, 105-134.

Kalmuss, D., Davidson, A., \& Cushman, L. (1992). Parenting expectations, experiences and the transition to parenthood: A test of the violated expectations model. Journal of Marriage and the Family, 54, 516-526.

Keenan, K., \& Shaw, D. (1997). Developmental and social influences on young girls' early problem behavior. Psychological Bulletin, 121, 95-113.

Keller, T. E., Gilchrist, L., \& Spieker, S. J. (2000). Disrupted relationships: Prolonged separations between adolescent mothers and their children in the first three years of life. Unpublished manuscript, University of Washington.

Kerr, M., Tremblay, R. E., Pagani, L., \& Vitaro, F. (1997). Boys' behavioral inhibition and the risk of later delinquency. Archives of General Psychiatry, 54, 809-816.

Lahey, B. B., Waldman, I. D., \& McBurnett, K. (1999). Annotation: The development of antisocial behavior: An integrative causal model. Journal of Child Psychology and Psychiatry, 40, 669-682.

Lengua, L. J., West, S. G., \& Sandler, I. (1998). Temperament as a predictor of symptomatology in children: Addressing contamination of measures. Child Development, 69, 164-181.

Lewis, M., Feiring, C., McGuffog, C., \& Jaskir, J. (1984). Predicting psychopathology in six-year-olds from early social relations. Child Development, 55, 126-136.

Lewis, R. J., Dlugokinski, E. L., Caputo, L. M., \& Griffin, R. B. (1988). Children at risk for emotional disorders: Risk and resource dimensions. Clinical Psychology Review, 8, 417-440.

Li, F., Duncan, T. E., Duncan, S. C., \& Acock, A. (2001). Latent growth modeling of longitudinal data: A finite growth mixture modeling approach. Structural Equation Modeling, 8, 493-530.

Little, R. J. A., \& Rubin, D. B. (1987). Statistical analysis with missing data. New York: Wiley.

Loeber, R., \& Hay, D. (1997). Key issues in the development of aggression and violence from childhood to early adulthood. Annual Review of Psychology, 48, 371-410.

Loeber, R., \& Keenan, K. (1994). Interactions between conduct disorder and its comorbid conditions: Effects of age and gender. Clinical Psychology Review, 14, 497-523.

Lyons-Ruth, K. (1996). Attachment relationships among children with aggressive behavior problems: The role of disorganized early attachment patterns. Journal of Consulting and Clinical Psychology, 64, 64-73.

Lyons-Ruth, K., Alpern, L., \& Repacholi, B. (1993). Disorganized infant attachment classification and maternal psychosocial problems as predictors of hostileaggressive behavior in the preschool classroom. Child Development, 64, 572-585.

Maccoby, E. E., \& Martin, J. A. (1983). Socialization in the context of the family: Parent-child interaction. In 
E. M. Hetherington (Ed.), Handbook of child psychology: Vol. 4. Socialization, personality, and social development (4th ed., pp. 1-101). New York: Wiley.

Magnusson, D. (1995). Individual development: A holistic, integrated model. In P. Moen, G. H. Elder, Jr., \& K. Luscher (Eds.), Examining lives in context: Perspectives on the ecology of human development ( $\mathrm{pp}$. 19-60). Washington, DC: American Psychological Association.

Magnusson, D. (1998). The logic and implications of a person-oriented approach. In R. B. Cairns, L. R. Bergman, \& J. Kagan (Eds.), Methods and models for studying the individual (pp. 33-63). Thousand Oaks, CA: Sage.

Main, M., \& Cassidy, J. (1988). Categories of response to reunion with the parent at age 6: Predictable from infant attachment classifications and stable over a 1-month period. Developmental Psychology, 24, $415-426$.

Main, M., \& Hesse, E. (1990). Parents' unresolved traumatic experiences are related to infant disorganized attachment status: Is frightened and/or frightening parental behavior the linking mechanism? In M. Greenberg, D. Cicchetti, \& E. M. Cummings (Eds.), Attachment in the preschool years: Theory, research, and intervention (pp. 161-182). Chicago: University of Chicago Press.

Main, M., \& Solomon, J. (1990). Procedures for identifying infants as disorganized/disoriented during the Ainsworth Strange Situation. In M. T. Greenberg \& D. Cicchetti \& E. M. Cummings (Eds.), Attachment in the preschool years: Theory, research and intervention (pp. 121-160). Chicago: University of Chicago Press.

Moffitt, T. E. (1993). Adolescence-limited and life-coursepersistent antisocial behavior: A developmental taxonomy. Psychological Review, 100, 674-701.

Munson, J. A., McMahon, R. J., \& Spieker, S. J. (2001). Structure and variability in the developmental trajectory of children's externalizing problems: Impact of infant attachment, maternal depressive symptomatology, and child sex. Development and Psychopathology, 13, 277-296.

Muthén, B. (2001). Second-generation structural equation modeling with a combination of categorical and continuous latent variables: New opportunities for latent class/latent growth modeling. In L. Collins \& A. Sayer (Eds.), New methods for the analysis of change (pp. 291-322). Washington, DC: American Psychological Association.

Muthén, B., \& Muthén, L. K. (2000). Integrating personcentered and variable-centered analyses: Growth mixture modeling with latent trajectory classes. Alcoholism: Clinical and Experimental Research, 24, 882-891.

Muthén, L. K., \& Muthén, B. O. (1998). Mplus user's guide. Los Angeles: Author.

Osofsky, J. D., Hann, D. M., \& Peebles, C. (1993). Adolescent parenthood: Risks and opportunities for mothers and infants. In C. H. Zeanah, Jr. (Ed.), Handbook of infant mental health (pp. 106-119). New York: Guilford Press.

Patterson, G. R., Capaldi, D., \& Bank, L. (1991). An early starter model for predicting delinquency. In D. Pepler $\&$ K. Rubin (Eds.), The development and treatment of childhood aggression (pp. 139-168). Hillsdale, NJ: Erlbaum.

Patterson, G. R., DeBaryshe, B. D., \& Ramsey, E. (1989).
A developmental perspective on antisocial behavior American Psychologist, 44, 329-335.

Pianta, R. C. (Ed.). (1992). Beyond the parent: The role of other adults in children's lives. San Francisco, CA: Jossey-Bass.

Radke-Yarrow, M., McCann, K., DeMulder, E., Belmont, B., Martinez, P., \& Richardson, D. T. (1995). Attachment in the context of high-risk conditions. Development and Psychopathology, 7, 247-265.

Radloff, L. S. (1977). The CES-D scale: A self-report depression scale for research in the general population. Applied Psychological Measurement, 1, 385-401.

Radloff, L. S. (1991). The use of the Center for Epidemiological Studies Depression Scale in adolescents and young adults. Journal of Youth and Adolescence, 20 , 149-166.

Raftery, A. E. (1995). Bayesian model selection in social research. Sociological Methodology, 25, 111-163.

Reid, J. B. (1993). Prevention of conduct disorder before and after school entry: Relating interventions to developmental findings. Development and Psychopathology, 5, 243-262.

Renken, B., Egeland, B., Marvinney, D., Mangelsdorf, S., \& Sroufe, L. A. (1989). Early childhood antecedents of aggression and passive-withdrawal in early elementary school. Journal of Personality, 57, 257-281.

Richters, J. E., \& Saltzman, W. (1990). Survey of exposure to community violence: Self report version. Rockville, MD: National Institute of Mental Health.

Roberts, R. E., Lewinsohn, P. M., \& Seeley, J. R. (1991). Screening for adolescent depression: A comparison of depression scales. Journal of the American Academy of Child and Adolescent Psychiatry, 30, 58-66.

Robins, L. N. (1991). Conduct disorder. Journal of Child Psychology and Psychiatry, 32, 193-212.

Rosenberg, M. (1965). Society and the adolescent selfimage. Princeton, NJ: Princeton University Press.

Rothbart, M. K., \& Bates, J. E. (1998). Temperament. In N. Eisenberg (Ed.), Handbook of child psychology: Vol. 3. Social, emotional, and personality development (5th ed., pp. 105-176). New York: Wiley.

Rothbaum, F., \& Weisz, J. R. (1994). Parental caregiving and child externalizing behavior in nonclinical samples: A meta-analysis. Psychological Bulletin, 116, $55-74$.

Rutter, M. (1985). Resilience in the face of adversity: Protective factors and resistance to psychiatric disorder. British Journal of Psychiatry, 147, 598-611.

Rutter, M. (1990). Psychosocial resilience and protective mechanisms. In J. Rolf, A. S. Masten, D. Cicchetti, K. H. Nuechterlein, \& S. Weintraub (Eds.), Risk and protective factors in the development of psychopathology. New York: Cambridge University Press.

Rutter, M. (1995). Clinical implications of attachment concepts: Retrospect and prospect. Journal of Child Psychology and Psychiatry and Allied Disciplines, 36, 549-571.

Rutter, M., Cox, A., Tupling, C., Berger, M., \& Yule, W. (1975). Attainment and adjustment in two geographical areas: 1 . The prevalence of psychiatric disorder. British Journal of Psychiatry, 126, 493-509.

Sameroff, A. J., Seifer, R., \& Bartko, W. T. (1997). Environmental perspectives on adaptation during childhood and adolescence. In S. S. Luthar \& J. A. Burack (Eds.), Developmental psychopathology: Perspectives on adjustment, risk, and disorder (pp. 507-526). New York: Cambridge University Press. 
Sanson, A., Oberklaid, F., Pedlow, R., \& Prior, M. (1991). Risk indicators: Assessment of infancy predictors of pre-school behavioural maladjustment. Journal of Child Psychology and Psychiatry, 32, 609-626.

Schafer, J. L., \& Graham, J. W. (2002). Missing data: Our view of the state of the art. Psychological Methods, 7 , $147-177$.

Seattle-King County Department of Public Health. (1998, May). Epidemiology, planning and evaluation. Seattle, WA: Author.

Seifer, R., Sameroff, A. J., Barrett, L. C., \& Krafchuk, E. (1994). Infant temperament measured by multiple observations and mother report. Child Development, 64, 1478-1490.

Shaw, D. S., Gilliom, M., Ingoldsby, E. M., \& Nagin, D. S. (2003). Trajectories leading to school-age conduct problems. Developmental Psychology, 39, 189-200.

Shaw, D. S., Owens, E. B., Vondra, J. I., Keenan, K., \& Winslow, E. B. (1996). Early risk factors and pathways in the development of early disruptive behavior problems. Development and Psychopathology, 8, 679-700.

Shaw, D. S., \& Vondra, J. I. (1995). Infant attachment security and maternal predictors of early behavior problems: A longitudinal study of low-income families. Journal of Abnormal Child Psychology, 23, 335-357.

Shaw, D. S., Vondra, J. I., Hommerding, K. D., \& Keenan, K., Dunn, M. (1994). Chronic family adversity and early child behavior problems: A longitudinal study of low income families. Journal of Child Psychology and Psychiatry and Allied Disciplines, 35, 1109-1122.

Shaw, D. S., Winslow, E. B., Owens, E. B., \& Hood, N. (1998). Young children's adjustment to chronic family adversity: A longitudinal study of low-income families. Journal of the American Academy of Child and Adolescent Psychiatry, 37, 545-553.

Solomon, J., \& George, C. (1999). The measurement of attachment security in infancy and childhood. In J. Cassidy \& P. R. Shaver (Eds.), Handbook of attachment: Theory, research, and clinical applications (pp. 287-316). New York: Guilford Press.

Spieker, S. J., \& Bensley, L. (1994). Roles of living arrangements and grandmother social support in adolescent mothering and infant attachment. Developmental Psychology, 30, 102-111.

Spieker, S. J., Larson, N. C., Lewis, S. M., Keller, T. E., \& Gilchrist, L. (1999). Developmental trajectories of disruptive behavior problems in preschool children of adolescent mothers. Child Development, 70, 443-458.

Spieker, S. J., Larson, N. C., Lewis, S. M., White, R. D., \& Gilchrist, L. (1997). Children of adolescent mothers: Cognitive and behavioral status at age six. Child and Adolescent Social Work Journal, 14, 335-364.

Sroufe, L. A. (1997). Psychopathology as an outcome of development. Development and Psychopathology, 9, 251-268.

Sroufe, L. A., Carlson, E. A., Levy, A. K., \& Egeland, B. (1999). Implications of attachment theory for developmental psychopathology. Development and Psychopathology, 11, 1-13.

Sroufe, L. A., \& Rutter, M. (1984). The domain of developmental psychopathology. Child Development, 54, 17-29.
Stattin, H., \& Magnusson, D. (1996). Antisocial development: A holistic approach. Development and Psychopathology, 8, 617-645.

Stormshak, E. A., Bierman, K. L., \& the Conduct Problems Prevention Research Group. (1998). The implications of different developmental patterns of disruptive behavior problems for school adjustment. Development and Psychopathology, 10, 451-467.

Straus, M. A. (1974). Leveling, civility and violence in the family. Journal of Marriage and the Family, 36, 13-29. [addendum, pp. 442-445]

Straus, M. A. (1979). Measuring intrafamily conflict and violence: The Conflict Tactics Scales. Journal of Marriage and the Family, 41, 75-88.

Straus, M. A., \& Hamby, S. L. (1997). Measuring physical and psychological maltreatment of children with the Conflict Tactics Scale. In G. K. Kantor \& J. L. Jasinski (Eds.), Out of darkness: Contemporary perspectives on family violence (pp. 119-135). Thousand Oaks, CA: Sage.

Suess, G. J., Grossman, K. E., \& Sroufe, L. A. (1992). Effects of infant attachment to mother and father on quality of adaptation in preschool: From dyadic to individual organisation of self. International Journal of Behavioral Development, 15, 43-65.

Teti, D. M. (1999). Conceptualizations of disorganization in the preschool years: An integration. In J. Solomon \& C. George (Eds.), Attachment disorganization (pp. 213-242). New York: Guilford Press.

Thompson, R., Lamb, M., \& Estes, D. (1983). Stability of infant-mother attachment and its relationship to changing life circumstances in an unselected middle-class sample. Child Development, 53, 144-148.

Tremblay, R. E., LeMarquand, D., \& Vitaro, F. (1999). The prevention of oppositional defiant disorder and conduct disorder. In H. C. Quay \& A. E. Hogan (Eds.), Handbook of disruptive behavior disorders (pp. 525555). New York: Kluwer Academic/Plenum Press.

van IJzendoorn, M. V., Schuengel, C., \& BakermansKranenburg, M. J. (1999). Disorganized attachment in early childhood: Meta-analysis of precursors, concomitants, and sequelae. Development and Psychopathology, 11, 225-249.

Vaughn, B., Egeland, B., Sroufe, L. A., \& Waters, E. (1979). Individual differences in infant-mother attachment at twelve and eighteen months: Stability and change in families under stress. Child Development, 50, 971-975.

Ward, M. J., \& Carlson, E. A. (1995). Associations among adult attachment representations, maternal sensitivity, and infant-mother attachment in a sample of adolescent mothers. Child Development, 66, 69-79.

Wilcox, H., Field, T., Prodromidis, M., \& Scafidi, F. (1998). Correlations between the BDI and CES-D in a sample of adolescent mothers. Adolescence, 33, 565-574.

Youngstrom, E., Izard, C., \& Ackerman, B. (1999). Dysphoria-related bias in maternal ratings of children. Journal of Consulting and Clinical Psychology, 67, 905-916.

Zeanah, C. H., Boris, N. W., \& Larrieu, J. A. (1997). Infant development and developmental risk: A review of the past 10 years. Journal of the American Academy of Child and Adolescent Psychiatry, 36, 165-178. 
Reproduced with permission of the copyright owner. Further reproduction prohibited without permission. 